\title{
Smart Biosensors for Cancer Diagnosis Based on Graphene Quantum Dots
}

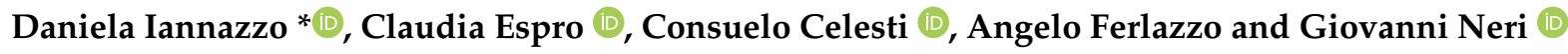

check for updates

Citation: Iannazzo, D.; Espro, C.;

Celesti, C.; Ferlazzo, A.; Neri, G.

Smart Biosensors for Cancer Diagnosis Based on Graphene Quantum Dots.

Cancers 2021, 13, 3194.

https://doi.org/10.3390/

cancers13133194

Academic Editor: Fiona M. Lyng

Received: 16 April 2021

Accepted: 24 June 2021

Published: 26 June 2021

Publisher's Note: MDPI stays neutral with regard to jurisdictional claims in published maps and institutional affiliations.

Copyright: (c) 2021 by the authors. Licensee MDPI, Basel, Switzerland. This article is an open access article distributed under the terms and conditions of the Creative Commons Attribution (CC BY) license (https:// creativecommons.org/licenses/by/ $4.0 /)$.
Department of Engineering, University of Messina, Contrada Di Dio, 98166 Messina, Italy; espro@unime.it (C.E.); ccelesti@unime.it (C.C.); angelo.ferlazzo@unime.it (A.F.); gneri@unime.it (G.N.)

* Correspondence: diannazzo@unime.it; Tel.: +39-090-6765569

Simple Summary: Graphene quantum dots, the next generation of graphene family, due to their remarkable physical and chemical properties, have been shown to be ideal sensing elements for the early diagnosis of cancer. In this review, we report the recent advances in the synthesis and functionalization of GQDs with different biomolecules able to selectively recognize and convert into a signal specific cancer biomarker, by means of optical, electrochemical and chemiluminescent biosensors. These sensors have shown to ensure the effective and sensitive detection of important cancer biomarkers such as antigens, enzymes, hormones, proteins, cancer related byproducts, biomolecules exposed on the surface of cancer cells and also changes in $\mathrm{pH}$. The developed biosensors can allow the effective diagnosis of cancer diseases as well as the evaluation of the anticancer therapy effectiveness.

Abstract: The timely diagnosis of cancer represents the best chance to increase treatment success and to reduce cancer deaths. Nanomaterials-based biosensors containing graphene quantum dots (GQDs) as a sensing platform show great promise in the early and sensitive detection of cancer biomarkers, due to their unique chemical and physical properties, large surface area and ease of functionalization with different biomolecules able to recognize relevant cancer biomarkers. In this review, we report different advanced strategies for the synthesis and functionalization of GQDs with different agents able to selectively recognize and convert into a signal specific cancer biomarkers such as antigens, enzymes, hormones, proteins, cancer related byproducts, biomolecules exposed on the surface of cancer cells and changes in $\mathrm{pH}$. The developed optical, electrochemical and chemiluminescent biosensors based on GQDs have been shown to ensure the effective diagnosis of several cancer diseases as well as the possibility to evaluate the effectiveness of anticancer therapy. The wide linear range of detection and low detection limits recorded for most of the reported biosensors highlight their great potential in clinics for the diagnosis and management of cancer.

Keywords: graphene quantum dots; cancer diagnosis; cancer biomarkers; biosensors

\section{Introduction}

Cancer diseases, characterized by the uncontrolled growth and spread of abnormal cells, are the second leading cause of death globally, behind cardiovascular diseases. The World Health Organization (WHO) estimated 18.1 million new cases in 2018 and 9.6 million cancer deaths [1]. Moreover, based on the projected population growth and aging, the global cancer burden is expected to nearly double in 2040 [2]. The severity of pathophysiological processes related to cancer and the dramatic ever-growing number of cancer deaths has the scientific community to find new breakthrough treatments and new tools for early cancer diagnosis [3,4]. The timely diagnosis of cancer diseases in early stage is a pivotal factor to increase the chances of treatment success and to reduce cancer-related deaths. Nowadays, the preliminary diagnosis is mainly based on high-end methods such as $\mathrm{X}$-ray, nuclear magnetic resonance, ultrasound based imaging, and computed and positronemission tomography, which may suffer from low sensitivity and/or low resolution and 
generally low ability to detect small numbers of cancer cells, ideally before the angiogenic switch [5]. The molecular diagnostic tools for the measurements of cancer biomarkers such as the enzyme-linked immunosorbent assay (ELISA), polymerase chain reaction (PCR), mass spectrometry (MS), chromatography and gel electrophoresis, show major advantages over image methods, requiring a thousand times lesser cell numbers [6]. However, these improved detection techniques require time-consuming procedures, skilled personnel, expensive instrumentation and the impracticality to perform the on-site detection in human biological medium, due to the needed sample processing procedures, handling conditions, and storage time, thus often leading to poor outcomes. The recent advances in nanotechnology have demonstrated great promise in revolutionizing cancer diagnostics by empowering miniaturized biosensors for the on-site early and efficient diagnosis [4,7]. Nanobiosensor technologies have a huge potential over conventional methods, such as the real-time analysis, low limits of detection (LOD), high-throughput screening, label-free detection and a small amount of sample to be analyzed [8]. Nanosized materials with dimensions in the range of 1-100 nm, derived from organic or inorganic sources, have been widely investigated to modify electrode surfaces in order to afford biosensors with improved reproducibility, selectivity and sensitivity $[9,10]$. Their surface modification with suitable functional groups, targeting biomolecules, drugs, and genes, allowed the development of advanced nanoplatforms for various applications in cancer detection and therapy [11]. The used nanomaterials were shown to be biocompatible, structurally suitable for sensors fabrication and endowed of strong adsorption ability [12]. Unlike conventional counterparts used for biosensing, materials in the nanoscale exhibit unique physicochemical characteristics such as quantum size and macroscopic quantum tunnel effect, large surface-to-volume ratios and ease surface functionalization, thus allowing the development of highly sensitive electrochemical, electrochemiluminescent, magnetic, gravimetric and optical biosensors [13].

Among the different classes of nanomaterials, the carbon based materials characterized by the presence of graphene structure, such as pristine graphene, graphene oxide (GO), reduced graphene oxide (rGO), carbon nanotubes (CNTs) and graphene quantum dots (GQDs) present several advantages due to their outstanding chemical, physical, and optical properties, leading to ultrasensitive and selective biosensor devices [14,15]. Graphene, the two-dimensional single atomic layer of $\mathrm{sp}^{2}$ hybridized carbon atoms, due to its remarkable properties including its large specific surface area, high mechanical strength, thermal conductivity, carrier mobility and electrical conductivity has attracted great interest in the scientific community for the development of low-cost and sensitive electrochemical biosensors and for many biological applications including drug and gene delivery and cancer phototherapy [11,16]. Its oxygenated derivatives, GO and rGO, because of the presence of oxygenated functional groups in their structure, have been conjugated with different types of inorganic nanoparticles, quantum dots, organic polymers and biologically relevant molecules, affording graphene-based biosensors endowed with great sensitivity, selectivity and operational stability, as well as advanced nanocomposites for drug delivery applications $[17,18]$. CNTs, constituted by graphene sheets rolled into a cylindrical shape, owing to their remarkable electronic and mechanical properties have been also widely exploited for a wide range of in vitro and in vivo applications, ranging from the development of highly sensitive biosensors to smart drug delivery systems for anticancer and antiviral therapy $[15,19,20]$. From a chemical point of view, the multiple sites of functionalization of these nanomaterials allow the covalent bonding with organic functionalities or biomolecules to the graphene surface or to oxygen groups present on the nanomaterials after oxidative treatments and/or their non-covalent electrostatic interactions, such as the $\pi-\pi$ interaction between aromatic compounds and the graphene structure. Moreover, the possibility offered by the multi-functionalization can also allow the concurrent or multiple detection of biomolecules [21].

Zero-dimensional GQDs, the next generation of the graphene family, received significant interest from academics and industries over the last few years [22]. Their remarkable 
physicochemical properties enabled novel and extraordinary applications in several fields including materials science, physics, chemistry, biology and medicine [23-25]. Unlike two-dimensional graphene, GQDs have a band gap because of quantum size effect and exhibit stable and size-dependent photoluminescence, which can be tuned during their synthesis, by controlling their size shape, doping with heteroatoms and the charge transfers between functional groups and the graphene surface [26,27]. GQDs have been loaded with drugs and tumor-targeting ligand units able to specifically recognize cancer receptors exposed on the cell surface by generating new therapies for efficient targeted delivery of anticancer agents as well as the development of new imaging agents for the in vitro and in vivo diagnosis of several types of cancer $[28,29]$. Due to their intrinsic optical properties, GQDs have been designed for application in photovoltaics, electro/photo/chemical catalysis, fabrication of flexible devices and biosensing [30]. Recent literature data report the use of GQDs functionalized with functional groups or biomolecules able to recognize cancer biomarkers or to detect tumor cells, as sensing elements for the selective early detection diagnosis of cancer (Figure 1).

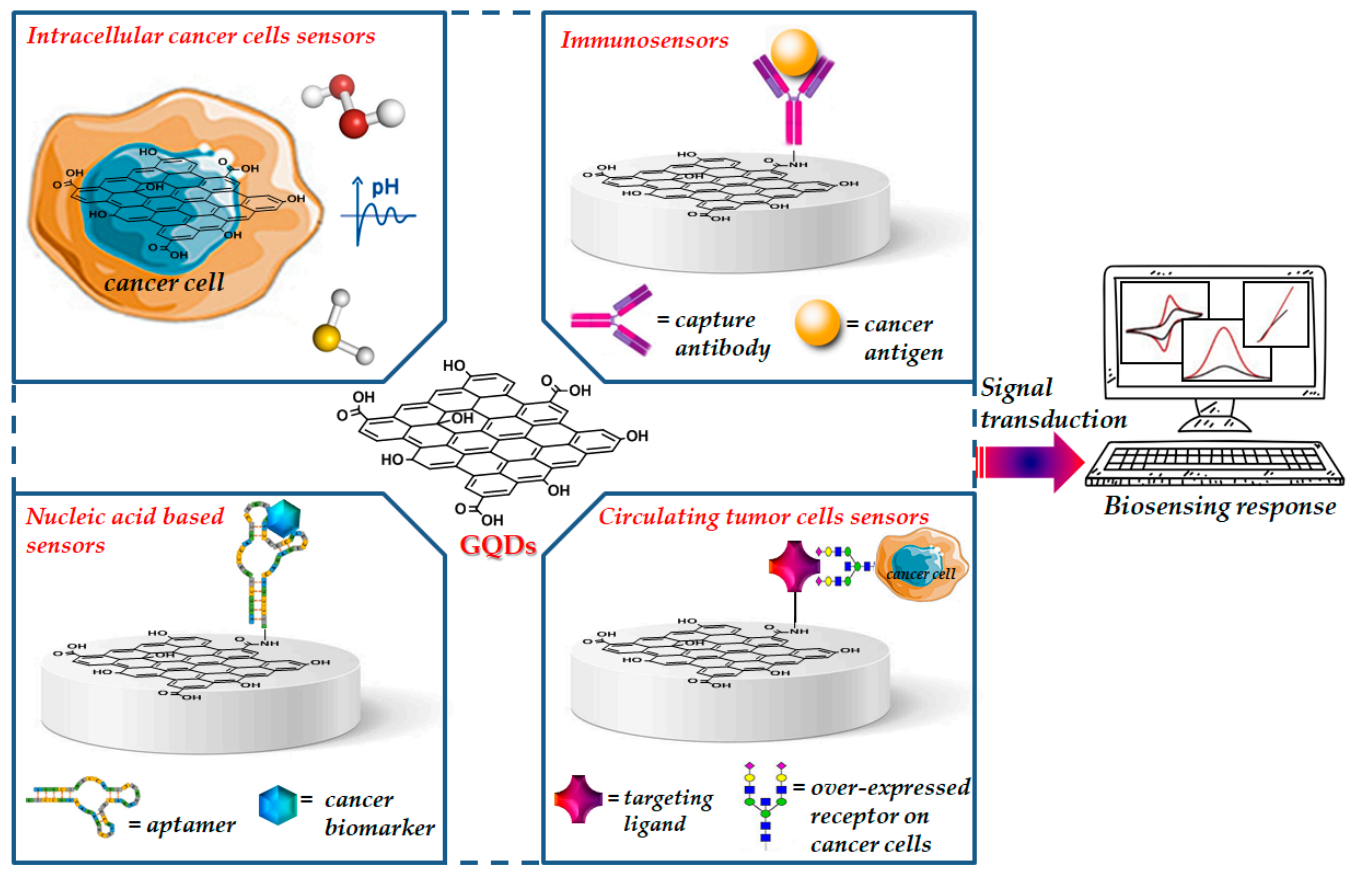

Figure 1. Representative image of functionalized GQDs for cancer biosensing.

The aim of this review is to report an overview of the recent advances, in the development of different classes of biosensors based on GQDs, for the cancer diagnosis, focusing the attention on the ideal properties of GQDs for biosensing and taking into account the methods used for their synthesis and functionalization procedures, and their possible use in clinics for the diagnosis and management of cancer.

\section{Suitable Properties of GQDs for Designing Nano-Scaled Biosensors}

GQDs, the new class of fluorescent materials from carbon nanomaterials family, possess ideal chemical and physical properties to be used and integrated in sensors for biological and medical applications [31]. From a morphological point of view, GQDs show the peculiar features of both graphene and carbon dots (CDs). CDs and GQDs are zero dimensional carbon based materials, both endowed with unique physicochemical properties associated with quantum size and edge effects. While CDs are mainly synthesized by bottom-up strategies and show spherical shape up to $10 \mathrm{~nm}$, GQDs are typically derived from materials where the $\mathrm{sp}^{2}$ carbon atoms are organized into a graphene structure [32]. The presence of a graphene structure and the large surface to volume ratio allow the ease 
functionalization to a large number of sites of graphene surface. Antibodies, proteins, nucleic acids and polymers have been covalently linked and/or conjugated via $\pi-\pi$ interaction to the graphene surface of GQDs, affording high selective and sensitive biosensors able to recognize biomarkers associated with various types of cancers [30,31]. The electronic and optical properties of GQDs make these nanomaterials particularly attractive in optoelectronics. These properties depend on their band gap because of quantum confinement, and are influenced by their size, number of layers, shape and edge configuration $[26,33]$. As a consequence, these properties can be modulated by using optimal carbon sources and size-controlling synthetic methodologies [34]. Kim et al. investigated the photoluminescence of GQDs, synthesized by various synthetic procedures, from near-ultraviolet to blue region and demonstrated the size-dependent shape/edge-state phenomenon affecting the absorption and PL behaviors of these nanomaterials [35]. As observed by high-resolution transmission electron microscopy (HRTEM), GQDs with sizes below $17 \mathrm{~nm}$ showed circular or elliptical shapes, while GQDs larger than $17 \mathrm{~nm}$ exhibited polygonal shape with the armchair edges (Figure 2). The authors observed the variation in absorption peak, which is consistent with the quantum confinement, whereas the PL peak energies exhibited non-monotonic behaviors as the size increased to $17 \mathrm{~nm}$. This anomalous PL behavior was attributed to the size-dependent shape and to the corresponding edge variations of GQDs, along with the scattering mechanism of graphene.

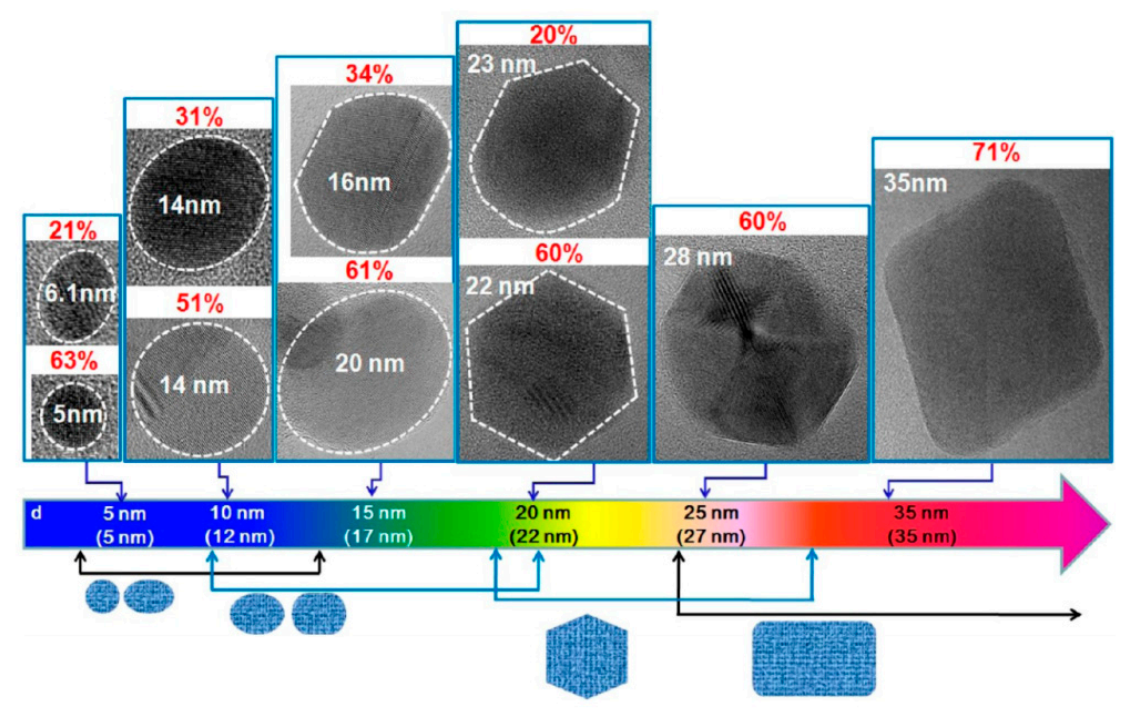

Figure 2. HRTEM images of GQDs reporting their major shapes and the corresponding populations (p) with the increasing average sizes. The dotted lines indicate the region of a GQD, and $\mathrm{p}$ is defined as the ratio of number of GQDs with a major shape for each average size. Reprinted with permission from Ref. [35]. Copyright 2012, American Chemical Society.

Most of the reported PL spectra of GQDs show colors ranging from blue to yellow [36]. This limiting narrow spectral coverage can be expanded by doping the energy donors GQDs with heteroatoms or functionalizing their surface [37]. The heteroatom doping of GQDs have been shown to expand the spectral coverage of GQDs to all visible wavelengths, improving their quantum yield (QY) and prolonging their fluorescence lifetime [38]. The ex situ surface functionalization has also proved to enrich their intrinsic state emission, thus opening new possibilities in the use of these zero-dimensional nanomaterials for various biomedical applications including biosensing and bioimaging [39].

Taking advantage of the electrochemical properties similar to graphene, GQDs have been widely used as active electrode materials in the field of electrochemical sensors [40]. The electrochemical platform is simple and smart, allowing it to easily perform a series of electrochemical techniques, such as cyclic voltammetry $(\mathrm{CV})$ and differential pulse voltammetry (DPV) and amperometric (AMP) measurements. The high performance of 
the GQDs-based electrochemical biosensors is related to the large surface-to-volume ratio, the abundance of hydrophilic/hydrophobic edges/basal planes, as well as the high conductivity of GQDs. The smart combination of chemiluminescence and electrochemistry led to a valuable analytical detection method known as electrochemiluminescence (ECL). ECL active GQDs are expected to have promising applications in the development of novel ECL biosensors, providing high sensitivity, good precision and acceptable stability [41]. Based on these considerations, in the following paragraphs, the relevant role of the employed synthetic methodologies to drive GQDs towards improved biosensing devices will be discussed.

\section{Recent Approaches for the Synthesis of GQDs as Biosensing Elements}

In order to obtain GQDs with ideal chemical, optical, and electronic properties for biosensing applications, several synthetic strategies have been reported [42,43]. In general, the methods for the synthesis of GQDs are classified into two categories, namely, topdown and bottom-up routes [23]. Some typical strategies are listed in Table 1. Top-down methodologies are based on the cutting and exfoliation of bulk graphene based materials such as graphite, graphene, GO, CNTs, carbon nanohorns, and carbon fibers by chemical or physical treatments, which include chemical exfoliation, hydrothermal and electrochemical methods [42,44-46]. These strategies are advantageous for the easily available starting materials and simple operation procedures, and generally afford to GQDs possessing many oxygen-containing functional groups, useful for subsequent functionalizations with bioactive molecules; however, these methods mainly suffer from low yields and lack of morphological control.

Table 1. Summary of typical approaches for the synthesis of GQDs as biosensing platforms.

\begin{tabular}{|c|c|c|c|}
\hline Approach & Method & Source & Ref. \\
\hline \multirow{10}{*}{ Top-down } & \multirow{6}{*}{ Hydrothermal } & graphite & [47] \\
\hline & & graphene & [48] \\
\hline & & graphene oxide & {$[49,50]$} \\
\hline & & corn powder & [51] \\
\hline & & cellulose & [52] \\
\hline & & rice husk & [53] \\
\hline & \multirow[t]{2}{*}{ Liquid exfoliation } & graphite & [54-57] \\
\hline & & graphite & [58-60] \\
\hline & \multirow[t]{2}{*}{ Electrochemical } & graphene oxide & [61] \\
\hline & & wood charcoal & [62] \\
\hline \multirow{16}{*}{ Bottom-up } & \multirow{7}{*}{ Hydrothermal } & pyrene & [63] \\
\hline & & pyrene and polyethyleneimine & {$[64]$} \\
\hline & & 1,3,6-trinitropyrene and borax & [65] \\
\hline & & citric acid & {$[66,67]$} \\
\hline & & glucose & {$[68,69]$} \\
\hline & & starch & {$[70]$} \\
\hline & & urea and glucose & [71] \\
\hline & \multirow{3}{*}{ Template methods } & 1,3,5-triamino-2,4,6-trinitrobenzene & {$[72]$} \\
\hline & & hexa-peri-hexabenzocoronene & [73] \\
\hline & & carbon disuphide & {$[74]$} \\
\hline & \multirow{3}{*}{ Pyrolysis } & L-glutamic acid & [75] \\
\hline & & citric acid & {$[76]$} \\
\hline & & trisodium citrate & [77] \\
\hline & \multirow{3}{*}{ Irradiation methods } & salicylic acid and pyridine-2,6-dicarboxylic acid & [78] \\
\hline & & glucose & [79] \\
\hline & & 1,3,6-trinitropyrene & {$[80]$} \\
\hline
\end{tabular}

The bottom-up strategies start from small aromatic compounds or other natural or synthetic carbon sources through several methodologies, which include stepwise solution chemistry, hydrothermal and solvothermal procedures, pyrolysis, microwave assisted 
methods, UV and electron beam irradiation [42,44]. These latter methods allow a more accurate control on the morphology, size, shape and generally afford to nanomaterials endowed with superior optical properties; conversely, these strategies are hindered by the need of expensive aromatic precursors and by complicated stepwise pathways.

\subsection{Top-Down Approaches}

The top-down methodologies for the synthesis of GQDs can be described as "defectmediated fragmentation processes". In these synthetic strategies, the formation of defects in the materials surface induce the tunable evolution of oxygen functional groups, which in turn can act as reactive sites, allowing the formation of very small graphene fragments [81]. The size, shape and amount of oxygen containing groups depend on the used carbon precursor and cutting methodology. The hydrothermal techniques for the synthesis of GQDs starting from graphene based materials are generally based on the use of strong oxidizing agents such as $\mathrm{H}_{2} \mathrm{SO}_{4}, \mathrm{HNO}_{3}$ and $\mathrm{H}_{2} \mathrm{O}_{2}$, affording nanodots with a high degree of oxygen containing groups [82]. GQDs synthesized following these procedures have been employed for different biosensing applications such as the detection of biomarkers of depression [47], the selective sensing of mercury ions [48] and $\mathrm{H}_{2} \mathrm{O}_{2}$ [49]. Hydrogen peroxide as etching agent and ammonia were also used for the synthesis of GQDs using GO as the starting material. The obtained GQDs have been used as basic components of a surface-enhanced Raman scattering (SERS) substrate for the detection of banned dye pollutants [50]. GQDs have also been successfully synthesized by employing biomass carbon sources such as corn powder [51], cotton cellulose [52] or rice husk biomass [53], and were employed as down conversion materials in dye-sensitized solar cells (DSSCs), in bioimaging and for $\mathrm{Fe}^{3+}$ sensing, respectively.

One of the most investigated methods for the synthesis of graphene based materials is the chemical exfoliation of layered bulk materials by chemical reactions involving intercalants such as acids, bases, inorganic salts, oxidizing agents, and reactive functional molecules [83-87]. Liu et al. synthesized GQDs with pure $\mathrm{sp}^{2}$ carbon crystalline structure by chemical exfoliation of graphite nanoparticles in organic solvents [54]. A oneand two-step chemical exfoliation route using $\mathrm{KMnO}_{4}$ was also investigated for the synthesis of GQDs starting from graphite flake powders and carbon nanotubes affording nanomaterials with different oxidation levels and PL excitation performances [55]. An ultrasound assisted liquid exfoliation method was used by Sarkar et al. for the synthesis of photoluminescent GQDs starting from graphite powder and using ethyl acetoacetate as solvent, in a strong basic medium [56]. Zdrazil et al. synthesized in high yields, low defect blue fluorescent GQDs by micro-wave expansion and liquid phase exfoliation of graphite [57]. Electrochemical methods, through the use of selective oxidation and reduction reactions, allow to obtain GQDs with accurate size control, in simple, efficient and green reaction conditions $[58,59,61,88]$. A simple approach to the synthesis of GQDs with blue to green photoluminescence by electrochemical exfoliation of graphite rods was reported by Bahadur et al. [58]. An environmentally friendly, electrochemical synthesis of glycine functionalized GQDs based on the direct exfoliation and oxidation from graphite rods was reported by Zhi et al. [61]. The synthesized bright yellow nanomaterials showed the ability to detect $\mathrm{Fe}^{3+}$ ions in a selective manner. In a recent work, Kalita et al. reported the electrochemical synthesis of GQDs with uniform size for the fabrication of soil moisture sensors [59]. Uniform-sized phosphorus and sulfur co-doped GQDs (P, SGQDs), were synthesized by the one-step electrolysis of graphite rods [61]. The synthesized GQDs were used as (ECL) immunosensors for the detection of okadaic acid in mussel samples. An environmentally friendly and single-step electrochemical synthesis of GQDs using as carbon source wood charcoal was reported by Kumar et al. [62]. The synthesized nanomaterials GQDs were investigated for the development of a colorimetric biosensor for the detection of $\mathrm{H}_{2} \mathrm{O}_{2}$ and glucose simultaneously. A green and scalable microplasma assisted electrochemical method for the synthesis of excitation-independent GQDs was recently reported by Joffrion et al. [60]. In this process, GQDs were exfoliated from a graphite 
rod, used as electrode in the electrochemical cell containing a glucose-water solution and assisted via microplasmas, thus affording GQDs with emission wavelength between violet and red, useful for photonic and electronic applications.

\subsection{Bottom-Up Approaches}

GQDs with controllable sizes, morphology and optical properties have been produced for biosensing applications by advanced bottom-up methods starting from small aromatic precursors or other carbon sources even originated by the degradation of bulk materials $[41-62,81-89]$. The most used bottom-up approaches for the synthesis of GQDs as sensing platforms can be classified in hydrothermal methods also assisted with microwave, template methods, and pyrolytic processes.

A gram-scale synthesis of fluorescent and water soluble GQDs based on a waterphase molecular fusion route under mild hydrothermal conditions was reported by Wang et al. [63]. The synthesized nanomaterials showed highly efficient excitonic fluorescence, strong excitonic absorption bands, large molar extinction coefficients and long-term photostability. In a similar way, Fan et al. reported a large-scale method to synthesize fluorescent and water-soluble GQDs with targeted imaging property by water-phase molecular fusion using pyrene and polyethyleneimine as precursors [64]. In order to improve the optical properties of GQDs, Xi et al. developed the synthesis of boron doped GQDs by a hydrothermal one-step molecular fusion between 1,3,6-trinitropyrene and borax in sodium hydroxide [65]. The synthesized B-GQDs were investigated as fluorescence probes for the detection of $\mathrm{Fe}^{3+}$ ion, phosphate and cytochrome C. Choi et al. synthesized cysteinefunctionalized GQDs through an hydrothermal process involving the carbonization of citric acid [66]. The produced green fluorescent GQDs were used for the selective $\mathrm{Hg}^{2+}$ ion detection. High-yield green-photoluminescent GQDs have been also produced by a hydrothermal method using only glucose and deionized water as precursors [68]. Dai et al. reported a green and one-pot hydrothermal method for the synthesis of GQDs using as reactants the natural polymer starch and water [70]. The synthesized nanodots have been successfully applied to cell imaging. Microwave assisted hydrothermal methods have been also used to combine the benefits of the hydrothermal technique with the advantages offered by microwave irradiation $[67,69,71,90]$. A microwave assisted hydrothermal method using glucose as precursor and without involving any harmful chemical in the process was recently investigated by Ray et al. for the synthesis of GQD-Au hybrid nanoparticles [71]. The synthesized GQDs were used for the reduction of $\mathrm{HAuCl}_{4}$, affording luminescent GQD-Au hybrid nanoparticles. Fresco-Cala et al. reported a one-pot microwave-assisted hydrothermal reaction starting from urea and glucose, in the presence of phosphoric acid [91].

Soft template methods are low cost and environmentally friendly procedures. These methods do not require separation and purification procedures, are suitable for largescale synthesis, and afford nanodots with controllable and uniform size [72-74,91]. Yang et al. synthesized GQDs by a soft-template approach using as carbon source and template 1,3,5-triamino-2,4,6-trinitrobenzene (TTAB) [73]. The produced nanomaterials exhibited green fluorescence, good solubility in water, and excellent biocompatibility, thus promoting their use in bio-imaging and optoelectronics. Monodispersed GQDs with strong blue PL emission have been synthesized through the soft-template method using as precursor hexa-peri-hexabenzocoronene (HBC) [74]. Gao et al. used carbon disulfide as precursor to synthesize fluorescent GQDs doped with sulfur [75].

The direct pyrolysis of small molecules has proved to be a facile bottom-up procedure to synthesize GQDs with homogenous size distribution [75-78]. Zhao et al. developed a simple synthetic method for the synthesis of GQDs by carbonizing, L-glutamic acid (Glu), using a heating mantle device [77]. The synthesized nanodots, proved to catalyze the reduction of $\mathrm{H}_{2} \mathrm{O}_{2}$ in the presence of a peroxidase substrate. Naik et al. reported a single-step synthesis of GQDs using the pyrolysis of citric acid, at different $\mathrm{pH}$ [78]. The authors found that the intensity of the fluorescence decreased with the increase of 
$\mathrm{pH}$. Blue-photoluminescent GQDs for cell imaging have been synthesized by Chen et al. through pyrolysis of trisodium citrate [79].

The irradiation methods used for the synthesis of GQDs represent green, simple and fast approaches for the large scale synthesis of these nanomaterials [79,80,92]. Zhu et al. reported a green approach through the free-radical polymerization reaction of the oxygen-containing aromatic compounds, salicylic acid and pyridine-2, 6-dicarboxylic acid, through ultraviolet irradiation [80]. In a recent work, Devendrappa et al. synthesized reduced GQDs (rGQDs) by using $365 \mathrm{~nm}$ UV irradiation for different hours to reduce oxygen containing glucose through a microwave assisted hydrothermal method [92]. The electrochemical behavior of the synthesized nanomaterials demonstrated the potential of rGQDs as active electrode materials. Wang et al. reported a room-temperature method for the synthesis of fluorescent and single-crystalline GQDs by electron-beam irradiation of 1,3, and 6-trinitropyrene in aqueous solutions of hydrazine hydrate, obtaining GQDs suitable for optoelectronics applications [93].

\section{Biosensors Based on GQDs for Cancer Detection}

Biosensors for cancer diagnosis are designed to recognize and convert into signal, specific cancer analytes such as antibodies, proteins, carcinoma antigens, nucleic acids, cancer related byproducts such as $\mathrm{H}_{2} \mathrm{O}_{2}$, proteins exposed on the surface of cancer cells and changes in $\mathrm{pH}[4,9,93]$. Recently, different strategies involving GQDs as sensing nanoplatforms have been developed for the early, fast and sensitive diagnosis of cancer (Table 2). The reported diagnostic tools have been shown to ensure the effective detection and monitoring of cancer diseases as well as the possibility to evaluate the effectiveness of anticancer therapy, thus demonstrating their great potential in clinics for the diagnosis and management of cancer. In the following paragraphs, we have summarized the most advanced strategies for the development of cancer biosensors based on the use of GQDs, by classifying the reported biosensors as intracellular cancer cell sensors, immunosensors, nucleic acid hybridization sensors and circulating tumor cell sensors.

Table 2. Summary of some recent GQDs-based biosensors for cancer detection.

\begin{tabular}{|c|c|c|c|c|c|}
\hline Sensing Material & Biological Material & Analyte & Detection Technique & Performance & Ref. \\
\hline GQDs & $\begin{array}{l}\text { L929, HT-1080, MIA, } \\
\text { PaCa-2, HeLa, MG-63 cells }\end{array}$ & $\mathrm{pH}$ & optical & $-49.96 \pm 3.5 \mathrm{mV} / \mathrm{pH}$ & [94] \\
\hline S-N-doped GQDs & $\begin{array}{l}\text { mice bearing PANC-1, A549 } \\
\text { HepG2 U87MG. HeLa cells }\end{array}$ & $\mathrm{pH}$ & optical & switch point at $\mathrm{pH} 6.8$ & [95] \\
\hline GQDs-DNPTYR & MCF-7 cells & $\mathrm{H}_{2} \mathrm{~S}$ & optical & LOD: 2 nM. & [96] \\
\hline RBD-GQDs & Pancreatic CSCs, HeLa cells & $\mathrm{Fe}^{3+}$ & optical & LOD: $0.02 \mu \mathrm{M}$ & [97] \\
\hline GQDs-cAb & - & CA-125 & chemiluminescence & LOD: $0.05 \mathrm{U} \mathrm{mL}^{-1}$ & [98] \\
\hline Ag-DPA-GQDs & plasma & CA-125 & electrochemical & LOD: $0.001 \mathrm{U} \mathrm{mL}^{-1}$ & [99] \\
\hline PtPd/N-GQDs@Au & serum & CEA & electrochemical & LOD: 2 fg $/ \mathrm{mL}$ & [100] \\
\hline GQDs@Au & serum & CEA & electrochemiluminescence & LOD: 3.78 fg/mL & [101] \\
\hline N,S-GQDs@Au-PANI & serum & CEA & electrochemical & LOD: $0.01 \mathrm{ng} / \mathrm{mL}$. & [102] \\
\hline amine-N-GQDs@Au & serum & NSE & optical & LOD: $0.09 \mathrm{pg} \mathrm{mL} \mathrm{mL}^{-1}$ & [39] \\
\hline CysA/Au NSs/GQDs & plasma, MCF-7 cells & CA $15-3$ & electrochemical & LOD: $0.11 \mathrm{U} / \mathrm{mL}$ & [103] \\
\hline P-Cys-GQDs-GNPs & $\begin{array}{c}\text { plasma, L929, HCT PC-3, } \\
\text { MCF-7 cells }\end{array}$ & p-53 & electrochemical & LOD: $0.065 \mathrm{fM}$ & [104] \\
\hline MWCNTs/GQDs & $\begin{array}{c}\text { lysates from } \\
\text { colorectal cancer }\end{array}$ & IL-13R $\alpha 2$ & electrochemical & LOD: $0.8 \mathrm{ng} \mathrm{mL}^{-1}$ & [105] \\
\hline MWCNTs/GQDs & $\begin{array}{l}\text { lysates from breast and } \\
\text { colorectal cancer }\end{array}$ & IL-13R $\alpha 2$ CDH-17 & amperometric & $\begin{array}{c}\text { LOD: } 1.4 \mathrm{ng} / \mathrm{mL} \\
\text { (IL-13sR } \alpha 2) ; \\
0.03 \mathrm{ng} / \mathrm{mL}(\mathrm{CDH}-17)\end{array}$ & [106] \\
\hline GQDs N-S/Au & serum & HCG & electrochemical & LOD: $12.5 \mathrm{fg} \mathrm{mL}^{-1}$ & [107] \\
\hline GQDs-IL-NF & serum & CEA & electrochemical & LOD: $0.34 \mathrm{fg} \mathrm{mL}^{-1}$ & [108] \\
\hline GQD/AuNP/NG/ & serum & CEA & electrochemical & LOD: $3.2 \mathrm{fg} \mathrm{mL}^{-1}$ & [109] \\
\hline GQDs & serum & PCa- exosomes & optical & LOD: $7.5 \mathrm{mg} \mathrm{ml}^{-1}$ & [110] \\
\hline GO/GQDs & - & $\begin{array}{l}\text { DNA } \\
p 16\end{array}$ & optical & LOD: 75.0 pM & [111] \\
\hline GQDs & - & $\begin{array}{l}\text { tumor-suppressor } \\
\text { gene }\end{array}$ & electrochemical & LOD: $0.10 \mathrm{pM}$ & [112] \\
\hline GQDs@ZIF-8 & - & M.SssI MTase & photoelectrochemical & LOD: $0.004 \mathrm{U} \mathrm{mL}^{-1}$ & [113] \\
\hline
\end{tabular}


Table 2. Cont.

\begin{tabular}{|c|c|c|c|c|c|}
\hline Sensing Material & Biological Material & Analyte & Detection Technique & Performance & Ref. \\
\hline AuNPs/GQDs/GO & serum & miRNA & electrochemical & $\begin{array}{c}\text { LOD: } 0.04 \mathrm{fM} \\
\text { (miRNA-21), } 0.33 \mathrm{fM} \\
\text { (miRNA-155), } 0.28 \mathrm{fM} \\
\text { (miRNA-210) }\end{array}$ & [114] \\
\hline NGQD@NC@Pd HNSs & $\begin{array}{l}\text { MDA-MB-231, HBL-100, } \\
\text { U87 cells }\end{array}$ & $\mathrm{H}_{2} \mathrm{O}_{2}$ & electrochemical & LOD: $20 \mathrm{nM}$ & [115] \\
\hline ConA-GQDs & MCF-7 cells & N-glycan & electrochemiluminescence & LOD: 21 cells / mL & [116] \\
\hline Apt@Fe $\mathrm{O}_{4} @ G Q D s / \mathrm{MoS}_{2}$ & $\begin{array}{l}\text { Hep G2, A549, } \\
\text { HEK } 293 \text { cells }\end{array}$ & EpCAM & optical & LOD: $1.19 \mathrm{nM}$, & [117] \\
\hline
\end{tabular}

\subsection{Intracellular Cancer Cells Sensors}

A universal strategy for detecting cancers of different origins could be achieved by using $\mathrm{pH}$ probes able to discriminate the differences in cellular environments of healthy or cancer cells. This difference in $\mathrm{pH}$ is due to the Warburg effect, leading to the lactic acid accumulation in rapidly growing tumor cells. In fact, because of acidosis, the pH values of healthy cells and tissues, usually found between 7.0 and 7.4, in solid tumors, regardless of their origin, decreases to $\mathrm{pH}$ values in the range of 6.4-6.8 [118]. Several authors demonstrated the change of photoluminescence observed in GQDs in response to change of $\mathrm{pH}$ in cellular medium [94,95]. Kumawat et al. reported the use of photoluminescent GQDs synthesized from grape seeds, for the effective intracellular $\mathrm{pH}$ mapping, in order to understand the various physiological phenomena occurring in the cancer cell microenvironment [95]. The authors demonstrated the ability of nanomaterials to enter cell nucleus in different cell lines (L929, HT-1080, MIA, PaCa-2, HeLa, and MG-63 cells), thus acting as a potential nucleus labelling agent. Optical sensing measurements, showed a gradual decreasing pattern in the PL intensity over $\mathrm{pH} 2$ to $\mathrm{pH} 13$ with response time of $\sim 1 \mathrm{~min}$ and sensitivity of $-49.96 \pm 3.5 \mathrm{mV} / \mathrm{pH}$, thereby demonstrating the potential of this system as a $\mathrm{pH}$ sensing agent. A pH-responsive fluorescent system based on sulfur-nitrogen-doped GQDs able to exhibit a sharp fluorescence transition between green (at pH below 6.8) and blue (at pH above 6.8) was reported by Fan et al. [119].

The GQDs used in this study were produced by an electrochemical method, starting from graphite rods in sodium p-toluenesulfonate acetonitrile solution, leading to nanoparticles with uniform size (average diameter of $4 \mathrm{~nm}$ ) and high photostability. The authors speculated that in weak acidic environment, the protonated nitrogen present on the GQDs surface act as H-bond donor to form an intramolecular N-H-O hydrogen bond, which then interact with the oxygens of the adjacent sulfonic group; this hydrogen bond interaction led to the observed fluorescence switch. The ability of the nanomaterials to detect cancers of different origin at an early development stage was demonstrated by fluorescence imaging in mice bearing PANC-1, HepG2, A549, U87MG, and HeLa tumors. The reported PL emission from the tumor site, due to EPR effect, and the observed upconversion photoluminescence further highlighted the great potential of the system as a universal probe for image-guided surgery and cancer diagnosis. GQDs-based biosensors designed for cancer diseases include biosensors able to detect abnormal levels of small molecules, such as $\mathrm{H}_{2} \mathrm{~S}$ or $\mathrm{NO}$, which are normally related to several diseases, such as cancer, diabetes, liver cirrhosis and Alzheimer's disease $[119,120]$. Li et al. reported a fluorescent probe based on GQDs synthesized from pyrene, and covalently conjugated with 2,4-dinitrophenoxy-tyrosine (DNPTYR) for the real-time imaging of the intracellular level of $\mathrm{H}_{2} \mathrm{~S}$ triggered in response to stimulus [96]. This sensor worked like a turn-on probe for $\mathrm{H}_{2} \mathrm{~S}$, since the presence of this analyte was able to cleave the dinitrophenoxyl group, thus restoring the photoluminescence of the nanomaterial. The authors demonstrated in vitro the ability of this biocompatible and photostable system to measure dynamically in breast cancer cell line (MCF-7), the amount of $\mathrm{H}_{2} \mathrm{~S}$ at a concentration as low as $2 \mathrm{nM}$. $\mathrm{The} \mathrm{Fe}^{3+}$ ion is involved in different physiological and pathological processes, including anemia, liver damage, diabetes, neurodegenerative disorders and cancer [121]. In order to 
detect the concentration of $\mathrm{Fe}^{3+}$ in living cancer cells, Voelcker et al. synthesized a turn-on orange-red fluorescent biosensor based on rhodamine B functionalized GQDs (RBD-GQDs). The authors found for this fluorescent sensor, detection limits in pancreatic cancer stem cells (CSCs) as low as $0.02 \mu \mathrm{M}$ [97]. Moreover, after binding with the ion, the RBD-GQDs nanosystem showed orange-red fluorescence with $43 \%$ quantum yield, thus suggesting its possible use a labelling agent for cancer cells.

\subsection{Immunosensors}

Immunosensors are analytical devices able to measure signals in response to specific antibody-antigen interactions. This class of biosensors represent a valuable alternative to the clinically used tests for the detection of biomarkers such as the enzyme-linked immunosorbent assay (ELISA), which requires several separation steps and time-consuming processes. A large number of ultrasensitive and selective immunosensors have been developed using different kinds of transducers, exploiting changes in mass, heat, electrochemical or optical properties [122]. GQDs represent promising nanomaterials for biosensors development due to their large surface area, excellent electrical and thermal conductivity, possibility of doping with heteroatoms and the presence of several oxygen-containing functional groups that allow the formation of stable chemical bonds with different biologically relevant molecules $[30,40]$. Wu et al. developed an immunosensor for the detection of the ovarian cancer biomarker CA-125, by exploiting the chemiluminescence resonance energy transfer (CRET) to GQDs [98]. In this study, the nanodots synthesized by photo-Fenton method from $\mathrm{GO}$ were immobilized on amino-modified glass chips and covalently linked to the capture antibody (cAb), specific for the CA-125 antigen by amide conjugation. The signal transduction from the water soluble chemiluminescent reagent to the GQDs was based on CRET mechanism. The mechanism involved the use of the enzyme horseradish peroxidase (HRP), which in the absence of CA-125 antigen catalyzed the production of the reactive oxygen species (ROS) from $\mathrm{H}_{2} \mathrm{O}_{2}$ and oxidized luminol, thus generating the excited electrons. Then, when the electrons returned to the ground state, chemiluminescence occurred, emitting blue light. When the CA-125 antigen was present in the immunoassay, the formed antibody-antigen complex was exposed to Ab-HRP to form a sandwich structure composed of GQDs-cAb/CA-125/Ab-HRP. In this way, HRP is in close proximity to the GQDs, enabling the resonance energy transfer from the dianion of luminol to the GQDs and quenching the chemiluminescence. The biosensor showed a wide linear range of detection from $0.1 \mathrm{U} \mathrm{mL}^{-1}$ to $600 \mathrm{U} \mathrm{mL}^{-1}$ with a LOD of $0.05 \mathrm{U} \mathrm{mL}^{-1}$ for CA-125. In a recent work, Hasanzadeh et al. investigated the same antigen for the early detection of ovarian cancer in human plasma samples through the development of an electrochemical immunosensor [99]. In this study, nanodots synthesized through thermal pyrolysis of a mixture of citric acid and D-penicillamine (DPA-GQDs) were functionalized with silver nanoparticles and deposited on a GCE while the antibody of CA-125 was covalently linked to the conductive nano-ink modified with cysteamine functionalized $\mathrm{Au}$ nanoparticles (CysA) through a covalent bond between the carboxyl group of the antibody and the amine group of CysA-Au. The synthesized nano-ink Ag-DPA-GQDs was used to investigate the formation of an antigen-antibody complex, which was monitored using the differential pulse voltammetry (DPV) technique. The authors obtained a linear range of 0.001-400 $\mathrm{U} \mathrm{mL}^{-1}$ and LOD of $0.001 \mathrm{U} \mathrm{mL}^{-1}$.

The carcinoembryonic antigen (CEA) is an oncofetal glycoprotein with a molecular weight of $200 \mathrm{kDa}$, generally expressed by mucosal cells and over-expressed in various cancer diseases. This antigen represents one of the major tumor biomarkers used for the diagnosis of tumors, such as breast, lung, pancreatic, liver, colorectal, and gastric cancers [123]. The use of electrochemical sensor for CEA detection represents the most effective method to detect this antigen because of the high sensitivity, rapid response and easy to use. Yang et al. reported a ultrasensitive label-free electrochemical immunosensor for CEA detection, using nitrogen-doped GQDs supported PtPd nanoparticles and gold nanoparticles (PtPd/N-GQDs@Au) [100]. In this study, N-doped GQDs, synthesized from 
citric acid and dicyandiamide by hydrothermal method, were used for the stepwise selfassembly with the bimetallic nanoparticles and then, after amine functionalization, with the gold nanoparticles. The nanocomposite was deposited on a GCE and conjugated with anti-CEA by chemical bonding between PtPd NPs and the amine groups of antibody while BSA solution was used to suppress nonspecific binding sites between the antigen and the surface of electrode (Figure 3).

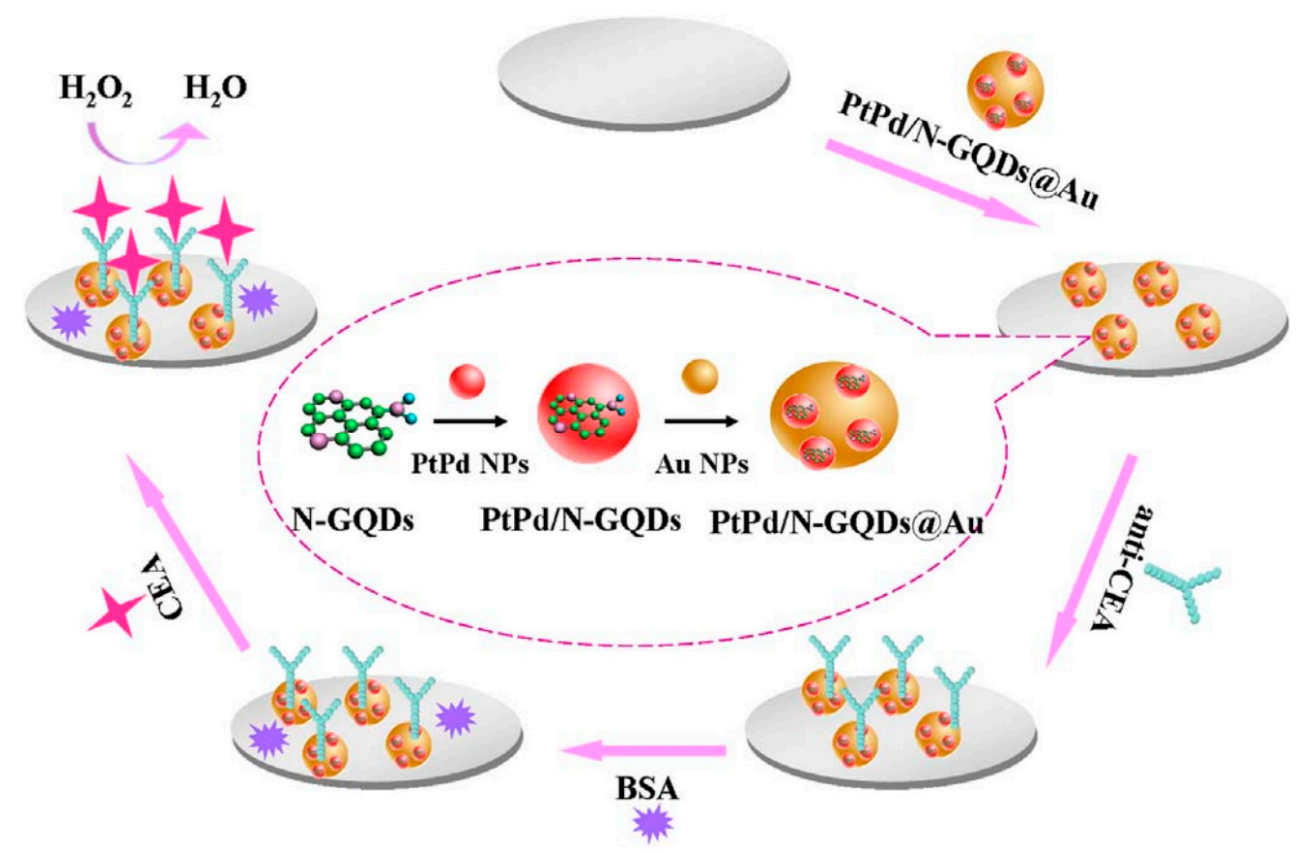

Figure 3. Label-free electrochemical immunosensor PtPd/N-GQDs@Au. Reprinted from Biosensors and Bioelectronics, ref. [100], copyright (2017), with permission from Elsevier.

The electronic interactions between NGQDs and the metallic nanoparticles contribute to the excellent electrocatalytic activity towards $\mathrm{H}_{2} \mathrm{O}_{2}$ reduction. The nanosystems were applied as transducing materials to efficiently conjugate capture antibodies and to amplify electrochemical signal by analyzing different concentrations of CEA in serum samples. The authors reported a wide linear range (from $5 \mathrm{fg} / \mathrm{mL}$ to $50 \mathrm{ng} / \mathrm{mL}$ ) and a very low detection limit $(2 \mathrm{fg} / \mathrm{mL}$ ). CEA antigen was also investigated as a cancer biomarker by Nie et al. by developing a sandwich-type electrochemiluminescence immunosensor [101]. The authors reported a signal amplification strategy based on poly(5-formylindole)/ reduced GO nanocomposite and Au nanoparticle decorated GQDs (GQDs@AuNP) as electrochemiluminescent probes. The $\mathrm{GO}$ nanocomposite facilitated the ion transport during the redox reactions and was used to immobilize the primary antibody (Ab1), while the Au decorated GQDs were loaded with the secondary antibody, which improved the electron transfer capability with stable intensity. Owing to the multiple signal amplification properties, this sandwich-type immunosensor showed good stability, reproducibility, specificity, a wide linear range of sensitivity for CEA detection (from $0.1 \mathrm{pg} / \mathrm{mL}$ to $10 \mathrm{ng} / \mathrm{mL}$ ) and a LOD of $3.78 \mathrm{fg} / \mathrm{mL}$ in human serum. Recently, Ganganboina et al. reported a label-free impedimetric immunosensor based on nitrogen and thiol-doped GQDs (N,S-GQDs) with size of 2-9 nm, synthesized by hydrothermal method from thiourea and citric acid [102]. The nanomaterials were used to decorate gold-embedded polyaniline (Au-PANI) nanowires by Au-thiol interaction and were covalently bound with anti-CEA antibody onto the $\mathrm{Pt}$ electrode. The detection principle was based on the change in impedance of the nanosystem after interaction with CEA; the formation of the CEA antibody-antigen complex showed to significantly increase the charge transfer resistance, thus affording a label-free immunoassay substrate for the impedimetric CEA detection. To evaluate the feasibility of the nanosystems for real-time biomedical application, the authors determined the antigen 
in commercial human serum samples. This immunosensor showed a wide linear range of detection (from 0.5 to $1000 \mathrm{ng} / \mathrm{mL}$ ) with a LOD of $0.01 \mathrm{ng} / \mathrm{mL}$.

The neuronspecific enolase (NSE) is a specific serum biomarker for the early diagnosis of small cell lung cancer (SCLC) [124]. Recently, Packirisamy et al. developed a fluorescent turn-on biosensor for the ultrasensitive detection of NSE based on functionalized GQDs as the energy donor system and gold nanoparticles (AuNPs) as the energy acceptor (antiNSE/amine-N-GQDs@AuNP) [39]. The amine-functionalized and nitrogen-doped GQDs with an average size of $\sim 3 \mathrm{~nm}$ were synthesized by hydrothermal method starting from citric acid and diethylenetriamine (DETA) and covalently conjugated to the monoclonal NSE antibody (anti-NSE). The mechanism of this fluorescent biosensor is based on the nanosurface energy transfer (NSET) between these antibody conjugated GQDs and the AuNPs mixed with the nanosystem (Figure 4). The blue fluorescence emission of the anti-NSE/GQDs system (ON state) was quenched by AuNPs, acting as highly efficient fluorescence acceptors (OFF state). The subsequent additions of NSE antigen to the composite solution increases the distance between the antibody conjugated system and the AuNPs, thus allowing the restoration of fluorescence (ON state). The composite showed a broad linear detection range $\left(0.1 \mathrm{pg} \mathrm{mL}^{-1}\right.$ to $\left.1000 \mathrm{ng} \mathrm{mL}^{-1}\right)$, and a low LOD $\left(0.09 \mathrm{pg} \mathrm{mL}^{-1}\right)$. Moreover, when this fluorescent biosensor was investigated in human serum samples, an excellent performance with an average recovery value of $94.69 \%$ was reported.

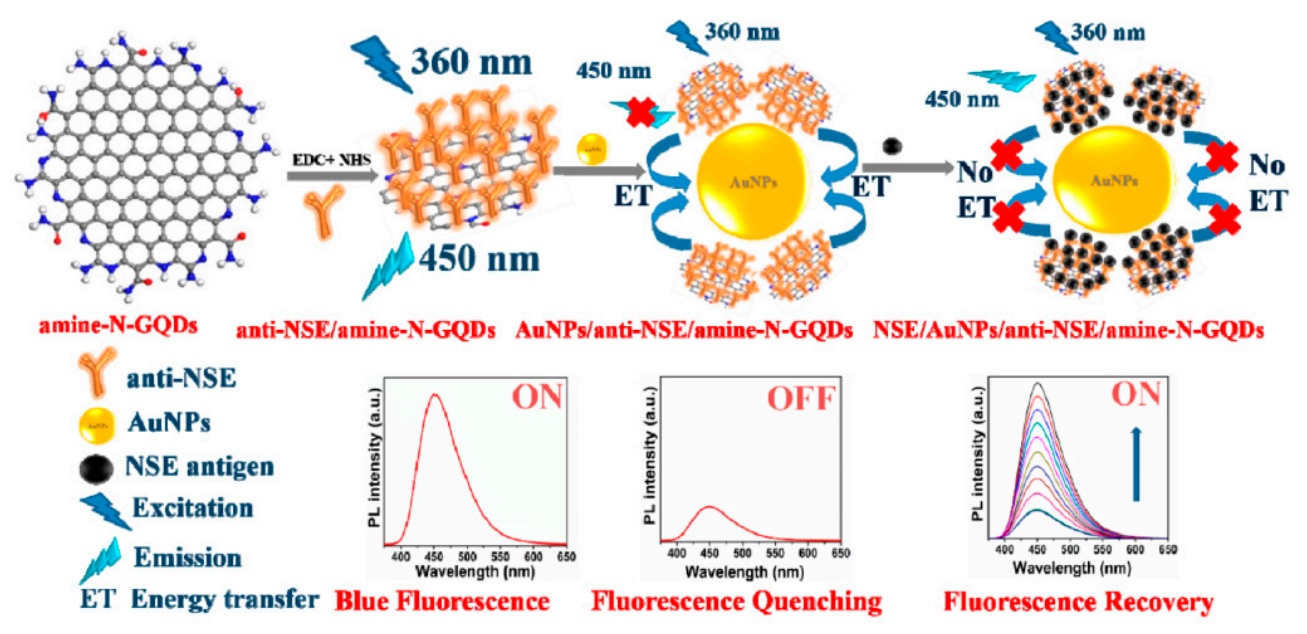

Figure 4. Mechanism of the anti-NSE/amine-N-GQDs@AuNP biosensor for small cell lung cancer biomarker detection. Reprinted with permission from ACS Applied Bio Materials, ref. [39]. Copyright (2020), American Chemical Society.

CA15-3 is the most commonly used tumor marker for the diagnosis of breast cancer [125]. Hasanzadeh et al. developed a label-free immunosensor based on gold nanosphere (Au NSs) electrochemically assembled on thiolated GQDs (CysA/Au NSs/GQDs) for the detection of CA 15-3 [103]. In this work, GQDs synthesized by pyrolyzing citric acid, were electrochemically deposited modified onto GCE and then functionalized with thiol groups and covalently loaded with gold nanoparticles by electrochemical assembly. The so developed nanosystem with $80-140 \mathrm{~nm}$ diameter and $20 \mathrm{~nm}$ height, provided a large surface area for the effective loading of CA 15-3, thereby increasing the number of binding events occurring between the antigen and antibodies. The authors found that under optimized experimental conditions, the immunosensor demonstrated good sensitivity and specificity, showing, in human plasma sample, a linear dynamic range of $0.16-125 \mathrm{U} / \mathrm{mL}$ and a LOD of $0.11 \mathrm{U} / \mathrm{mL}$. Moreover, the application of the biosensor performance to the assay of CA 15-3 malignant cell line lysates of human breast adenocarcinoma (MCF-7 cell line) showed peak currents linearly proportional to the MCF-7 cells concentration, thus highlighting this system as a valuable tool for the point-of-care diagnosis of breast cancer. The same research group, developed a ultrasensitive electrochemical immunosensor based on ternary signal amplification strategy, for the quantitation of the tumor suppressor protein p53 [104]. 
This protein is involved in many cancer types and is known to be a negative regulator of cell growth [126]. It was demonstrated that its alteration or inactivation by mutation or by interactions with oncogene products of DNA tumor viruses, can lead to cancer [127]. In this study, GQDs with a size distribution of $\sim 5 \mathrm{~nm}$, synthesized by pyrolisis of citric acid, were electrically deposited on the surface of poly-cysteine modified Au electrodes via interaction of the $\mathrm{NH}_{3}{ }^{+}$groups of cysteine with the oxygen-containing groups of GQDs. The subsequent sono-electrodeposition with GQDs/AuNPs (GNPs) allowed the covalent immobilization of the biotinylated p53-antibody to the nanocomposite film constituted by poly L-cysteine (P-Cys) as conductive matrix and GNPs as synergetic amplification element (P-Cys-GQDs-GNPs) (Figure 5). The biosensor was then used for the detection of p53 protein by using differential pulse voltammetry (DPV) and square wave voltammetry (SWV) techniques. The authors reported a linear range of detection $(0.000592-1.296 \mathrm{pM})$ and a low LOD of p53 in unprocessed human plasma (0.065 fM). The biosensor performance was also evaluated towards both normal and malignant cell line lysates (the normal cell line from mouse L929, the colon cancer cells HCT, the prostate cancer cell line PC-3, and the human breast adenocarcinoma cell line MCF7), showing excellent sensitivity and long-term stability.
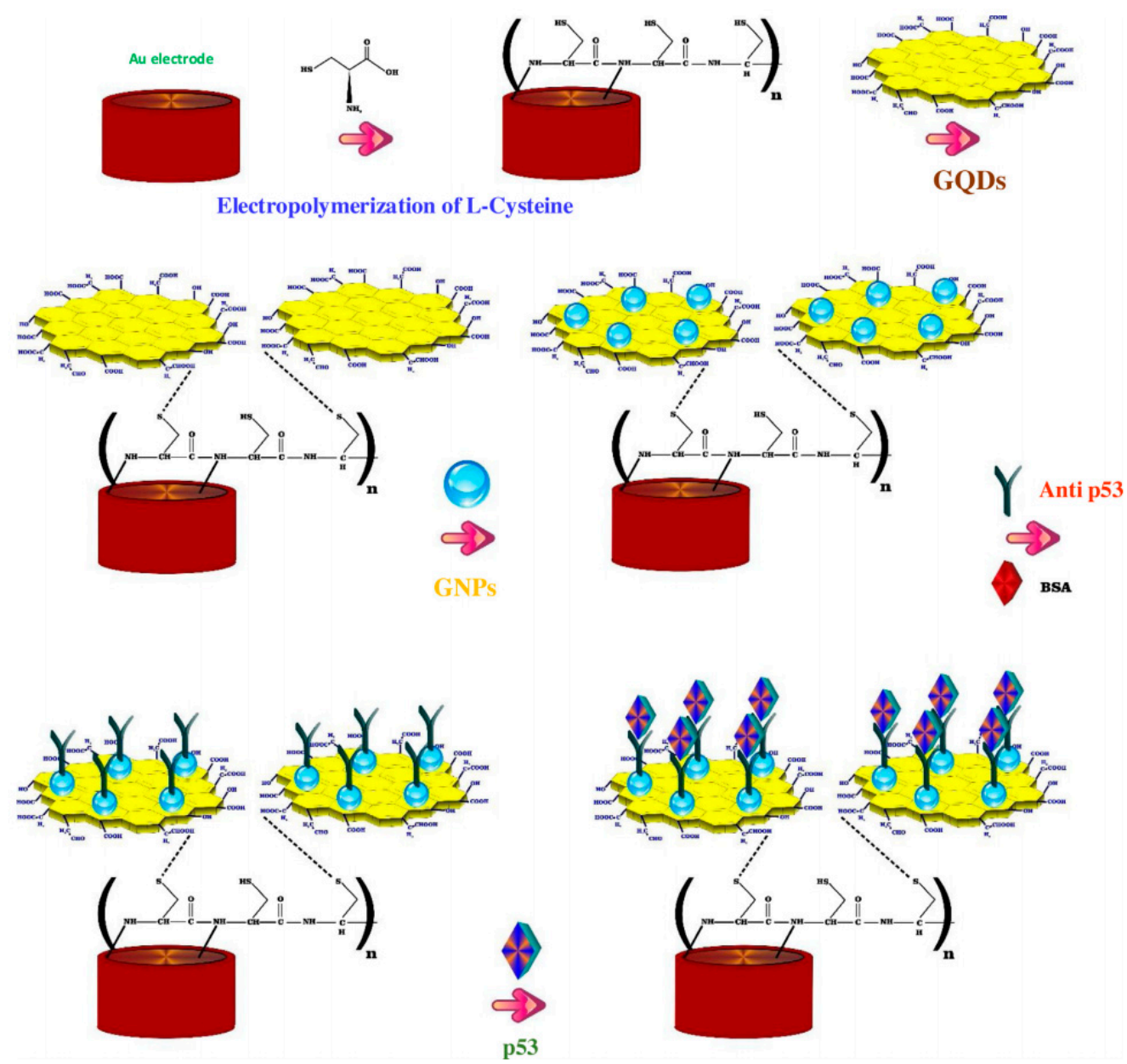

Figure 5. Fabrication steps of the label free electrochemical immunosensors for tumor suppressor protein p53 detection. Reprinted from International Journal of Biological Macromolecules, ref. [104], copyright (2018), with permission from Elsevier.

Over-expression of interleukin-13 receptor $\alpha 2$ (IL13R $\alpha 2$ ) is observed in several cancer diseases such as glioma, colorectal and pancreatic cancer [128]. Recently, Serafín et al. reported an integrated amperometric electrochemical immunosensor for the determination of 
IL13R $\alpha 2$, using an hybrid material composed of multiwalled CNTs (MWCNTs) and GQDs, synthesized by direct pyrolysis of citric acid [105]. The biotinylated IL13R $\alpha 2$ antibody was covalently linked to streptavidin-modified screen-printed electrodes (SPCE) through grafting with p-aminobezoic acid (p-ABA) using EDC/Sulfo-NHS chemistry. The MWCNTs/GQDs hybrid nanomaterial was used as a nanocarrier of multiple detector antibodies and horseradish peroxidase (HRP) molecules, improving the sensitivity assay due to the intrinsic peroxidase-like activity of GQDs. The amperometric detection of the analyte, using the system $\mathrm{H}_{2} \mathrm{O}_{2}$ /hydroquinone (HQ), allowed it to achieve a linear calibration range from 2.7 to $100 \mathrm{ng} \mathrm{mL}^{-1}$ of IL-13sR $\alpha 2$ and with a LOD value of $0.8 \mathrm{ng} \mathrm{mL}^{-1}$. The performance of this immunosensor was successfully applied to the determination of the target receptor in raw cellular lysates from different colorectal cancer cells and extracts of paraffin-embedded tissues from patients affected with colorectal cancer at different stages. In another work, the same group proposed a dual electrochemical immunoassay for the simultaneous detection of IL-13R $\alpha 2$ and cadherin-17 (CDH-17) an important cancer biomarker involved in several tumor processes with different metastatic potential and also a sensitive marker for gastric adenocarcinoma [129]. In this work, the MWCNT/GQDs-functionalized screen-printed dual carbon electrode (SPdCE) was assembled to form a sandwich sensor [106]. Following the same detection strategy previously described, the authors reported for this dual amperometric immunosensor the selective detection of the biomarkers IL-13sR $\alpha 2$ and $\mathrm{CDH}-17$, with respective LOD values of $1.4 \mathrm{ng} / \mathrm{mL}$ and $0.03 \mathrm{ng} / \mathrm{mL}$, respectively, as evaluated for lysates from breast and colorectal cancer cells.

The human chorionic gonadotropin (HCG) represents a diagnostic marker for the detection and monitoring of pregnancy, but it is also an extremely sensitive and specific marker for a variety of cancers including choriocarcinoma and extra-uterine malignancies [130]. Recently, Roushani et al. reported a label-free electrochemical immunosensor for the selective detection of HCG in human serum based on GQDs-N-S/Au modified SPCE [107]. In this study, nitrogen- and thiol-doped GQDs, synthesized from citric acid, were functionalized with amine and thiol groups after reaction with 3-aminopropyltriethoxysilane and 3-mercaptopropyl-triethoxysilane. The nanomaterial was casted on the surface of a modified SPCE, conjugated with Au nanoparticles to afford the AuNPs/GQDs$\mathrm{N}-\mathrm{S}$ system and then functionalized with the HCG antibody. Electrochemical analyses performed on this immunosensor showed the high sensitivity of the sensor towards the investigated biomarker with a linear communication in the range of 0.1 to $125 \mathrm{pg} \mathrm{mL}^{-1}$ and a LOD of $12.5 \mathrm{fg} \mathrm{mL}^{-1}$. The same procedure was successfully employed also for the detection of HCG in human serum samples.

Immunosensors that combine nucleic acid-based systems, allow to overcome some limitations related with the classical immunosensors, namely the type of substances that can be detected and sometimes, the difficulty to achieve sufficient sensitivity without additional amplification steps. Moreover, the production of monoclonal antibodies used in the specific antibody-antigen interactions is a costly and time-consuming procedure and unfortunately, these macromolecules can loss their specific activity after denaturation, thus requiring mild reaction conditions during the experimentations [131]. To overcome these limitations, immunosensors which uses DNA or RNA probes able to bind directly to selected targets as bioreceptors or to act as signal amplifiers have been developed [132]. New sensing methodologies use as biorecognition elements DNA or RNA aptamers, short synthetic single chain DNA or RNA oligonucleotides, which fold into three-dimensional structures. These molecules are able to react specifically and with high affinity with different small molecules and proteins [133].

Aptamers that can recognize the biomarker CEA have been isolated and investigated for in vivo imaging and diagnosis of cancer cells [134]. The aptamer strategy towards CEA analysis was successfully investigated by Zhao et al. by developing a combination of GO and aptamer labeled CdSe/ZnS quantum dots, by capillary electrophoresis [135]. The authors reported a linear relationship in the fluorescence intensity with concentrations of CEA in the range from 0.257 to $12.9 \mathrm{ng} / \mathrm{mL}$, and a LOD of $5 \mathrm{pg} / \mathrm{mL}$. The high sensitivity 
and specificity of the nanosystems was also proved in serum of patients. An electrochemical aptasensor for the high-sensitivity determination of CEA based on GQDs/ionic liquid-nafion (GQDs-IL-NF) composite film as the substrate for the DNA immobilization and $\mathrm{Pb}^{2+}$-dependent DNAzyme assisted target recycling signal amplification, was developed by Wang et al. [108]. In this work, GQDs with sizes in the range of 1.5-5 nm, synthesized from pyrolysis of citric acid, were mixed with nafion and with the ionic liquid 1-butyl-2,3-dimethylimidazolium tetrafluoroborate and then drop-coated on the surface of GCE; the subsequent treatment with aptamer solution allowed them to obtain the CEA electrochemical aptasensor. The mechanism of action of this sensor is based on a hairpin DNA constituted by the CEA-specific aptamer sequence and by a DNAzyme chain (Figure 6). In the presence of CEA, the hairpin DNA recognized the antigen, thus forming the CEA/aptamer complex; the subsequent interaction with the sequence of DNAzyme linked with methylene blue $(\mathrm{MB})$ allowed the introduction of a nick site in DNAzyme and in the presence of $\mathrm{Pb}^{2+}$ ions, the cleavage of the substrate chain into two fragments occurred. The CEA-aptamer complex was then released and the DNAzyme-assisted signal amplification reaction was performed, yielding a large number of MB substrates, thus producing the electrochemical signal. The authors reported a response current change proportional to the concentrations of CEA, with a linear range from $0.5 \mathrm{fg} \mathrm{mL}^{-1}$ to $0.5 \mathrm{ng} \mathrm{mL}^{-1}$, and a LOD of $0.34 \mathrm{fg} \mathrm{mL}^{-1}$. The aptasensor was also successfully applied in determining CEA in serum samples.

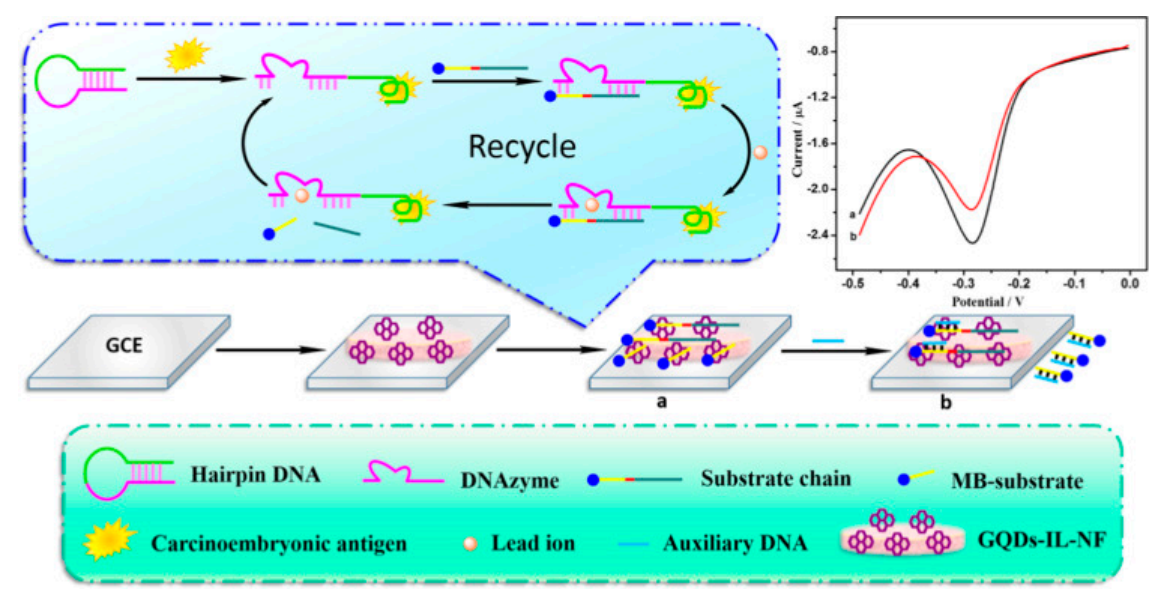

Figure 6. GQDs-IL-NF nanomatrix and DNAzyme-assisted recycling of target-aptamer complex for the sensitive electrochemical detection of CEA. Reprinted from Biosensors and Bioelectronics, ref [108], copyright (2018), with permission from Elsevier. (a) conjugation of GQDs with DNAzyme chain, (b) addition of MB substrate.

A sandwich-type electrochemical aptasensor for the sensitive detection of CEA was also developed by Zare et al. [109]. In this study, GQDs with sizes of $\sim 5.7 \mathrm{~nm}$ obtained from pyrolysis of citric acid were electrodeposited on the surface of a GCE firstly modified with N-doped graphene and with gold nanoparticles.

The CEA-binding aptamer was then covalently linked to the surface of the electrode by amide formation between the carboxyl groups of GQDs and the amino groups of the aptamer. Subsequently, the amino modified CEA aptamer II (ApII) linked to DNAzyme through linkage with glutaraldehyde (GA) was placed on the electrode surface to form a sandwich structure. Subsequently, different concentrations of CEA solutions were incubated onto the surface of the biosensor and the hemin-G4 acted as peroxidase-mimicking DNAzyme, catalyzing the electroreduction of hydrogen peroxide. The quantitative determination of CEA was obtained by DPV showing a linear response in the range of $10.0 \mathrm{fg} \mathrm{mL}^{-1}$ to $200.0 \mathrm{ng} \mathrm{mL}^{-1}$ and a low LOD of $3.2 \mathrm{fg} \mathrm{mL}^{-1}$.

Exosomes are extracellular vesicles surrounded by a lipid bilayer membrane with a diameter range of $30-150 \mathrm{~nm}$, and are secreted by almost all cells. These nano-vesicles 
are now considered as important mediators of intercellular communication, contributing to a wide range of biological processes, including cancer [136]. Exosomes are able to transfer bioactive macromolecules such as proteins, DNA, RNA, lipids and metabolites from the cells of origin to other cells. It was also demonstrated that these vesicles are more often released by cancer cells than healthy ones, thus leading to physiological changes and promoting tumor growth. Due to these interesting properties, exosomes have been recently investigated for the diagnosis and monitoring of cancer, as well as for the development of engineered vehicles for cancer treatment [137] Goreham et al. demonstrated the potential in using exosomes as nano-sized cancer biomarkers, using as detecting agent indium phosphide quantum dots conjugated with the CD63 antibody. This non-toxic conjugate demonstrated the ability to detect exosomes derived from a monocyte cell line (THP-1), expressing the protein CD63 [138]. Gold-carbon quantum dots (GCDs) conjugated with tumor-specific antibodies have been used for fluorescence imaging of exosomes, through immuno-reactions. The results of this study demonstrated the potential of this nanoprobe to investigate the intrinsic intracellular behavior of tumor derived exosomes [139]. Ramadan et al. developed graphene field-effect transistors decorated with carbon dots (CDs-GFET) and conjugated with CD-63 antibodies to target the CD-63 biomarkers present on the surface of the exosomes. The decoration with CDs have proved to allow a ultra-low LOD (100 particles/ $\mu \mathrm{L})$ [2]. The antibody of prostate-specific membrane antigen (PSMA) was recently used by Mahmoudifard et al. to label GQDs obtained from graphite in order to develop a fluorescent immunosensor able to detect prostate cancer (PCa) derived exosomes from blood serum [110]. In this study, the authors used a sandwich type process for the isolation and detection of exosomes, using a specialized nanofibrous membrane composed of polycaprolactone and gelatin which was conjugated with CD-63 antibodies and worked by capturing and holding exosomes during the washing processes, while the antibody conjugated GQDs identified the captured exosomes. The results obtained from photoluminescence studies showed a linear fluorescence quenching ability correlated to exosome concentration with a LOD of $7.5 \mathrm{mg} \mathrm{ml}^{-1}$. The system showed the ability to selectively recognize exosomes from mixtures containing different biomolecules and bio complexes, thus highlighting the potential of this approach for the immunosensing of cancer.

\subsection{Nucleic Acid Hybridization Sensors}

In recent years, DNA hybridization sensors emerged as promising clinical diagnostic devices for the detection of cancer and infectious diseases. These biosensors mainly consist of single-stranded DNA (ssDNA) probes immobilized on a transducer surface, which after the recognition with the complementary DNA target form a DNA double helix. This hybridization process can be converted into a quantified signal by the transducer for the optical, electrochemical, piezoelectric or thermal detection [140]. A highly selective and sensitive fluorescence sensing approach for DNA detection based on GQDs and GO oxide was reported by Feng et al. [111]. In this study, the authors combined the strong fluorescence of GQDs synthesized by acidic oxidation of graphite, the base pairing specificity of the ssDNA conjugated with the GQDs and the fluorescence resonance energy transfer (FRET) between the GQDs and GO to achieve quantitative analysis of the DNA target. The authors reported for this system a broad linear range of $6.7-46.0 \mathrm{nM}$ and a LOD of 75.0 pM DNA. Joshi et al. developed an electrochemical biosensor based on a simple screen-printed DNA sensor for the detection of the $p 16$ tumor-suppressor gene in prostate cancer [112]. In this work, GQDs synthesized from GO, were conjugated with the ssDNA sequence, and the subsequent hybridization with the ssDNA target was monitored by DPV and by electrochemical impedance spectroscopy (EIS). The system showed the ability to detect a single base mismatch in the presence of complementary and non-complementary oligonucleotide sequences, reporting a LOD of $0.10 \mathrm{pM}$. An electronic method for the quantification of the SEPT9 gene whose hypermethylation in the promoter region, is associated to the development of colorectal cancer (CRC), was recently reported 
by Jia et al. [141]. In this study, carbon dots synthesized by a one-step hydrothermal method starting from citric acid, have been drop-coated on the channel surface of liquid exfoliated graphene field effect transistor (LEG-FETs) to form the CD-modified LEG-FETs (CDs-LEG-FETs). Then, the target SEPT9 sequences were deposited on the system, allowing the recognition of the 5-methylcytosine $(5 \mathrm{mC})$ positions by the respective antibody and the responses were transduced according to the immunologic recognition and FET's sensing mechanism. The authors reported a detection sensitivity for the low-quantity of DNA samples as low as $2 \mathrm{ng}$. Chen et al. developed a signal-off photoelectrochemical biosensor for the evaluation of M.SssI methyltransferases (MTase) activity, an enzyme implied in DNA methylation and involved in cancer diseases [113]. In this study, zeolitic imidazolate framework-8 (ZIF-8) polyhedra were used as carriers of streptavidin labeled GQDs. Indium tin oxide (ITO) slice modified with $\mathrm{TiO}_{2}$, poly(diallyldimethylammonium chloride) and CdTe quantum dots (ITO/ $\mathrm{TiO}_{2} / \mathrm{CdTe}$ QDs) was functionalized with ssDNA via S-Cd bond and used as photoelectrode. Then, after hybridization with biotinylated ssDNA, the streptavidin-labeled GQDs@ZIF-8 polyhedra were introduced to the photoelectrode surface through the specific reaction between biotin and streptavidin. The GQDs@ZIF-8 polyhedra were shown to inhibit the photocurrent signal of the $\mathrm{ITO} / \mathrm{TiO}_{2} / \mathrm{CdTe}$ QDs electrode due to steric hindrance effect and also worked as peroxidase mimetics to catalyze the precipitation reaction of 4-chloro-1-naphthol, thus affording a depression in the photocurrent signal. This photocurrent decrease was quantitatively correlated with the enzyme activity with a linear response range, $0.005-150 \mathrm{U} \mathrm{mL}^{-1}$ and a LOD of $0.004 \mathrm{U} \mathrm{mL}^{-1}$.

MicroRNA (miRNA) is a small single-stranded RNA that plays an important role in different cellular processes including cancer progression [142]. An electrochemical biosensor based on a gold nanoparticles, GQDs and GO (AuNPs/GQDs/GO) for the detection of miRNA-21, miRNA-155, and miRNA-210 biomarkers in human serum was recently reported by Ounnunkad et al. [114]. In this work, the authors used three redox species (anthraquinone, methylene blue and polydopamine) to capture miRNA probes able to hybridize with the complementary targets, miRNA-21, miRNA-155, and miRNA210, respectively. This multiplex label-free miRNA biosensor demonstrated excellent performance for the simultaneous miRNA sensing, also distinguishing the miRNA target from other interfering oligonucleotides. The authors reported a wide linear range of 0.001 to $1000 \mathrm{pM}$ and the low LODs of $0.04,0.33$, and $0.28 \mathrm{fM}$ for the detection of miRNA21, miRNA-155, and miRNA-210, respectively.

\subsection{Circulating Tumor Cells Sensors}

The early and selective diagnosis of circulating tumor cells (CTC) is an important challenge in oncotherapy since when cancer cells are released from the primary tumor into the bloodstream, they can be considered the main promoters of metastasis. Thus, their evaluation and quantification are important issues to understand the tumor biology and to improve the clinical treatment of cancer diseases [143]. The developed sensing methodologies are mainly based on the detection of specific receptors over-expressed on the surface of cancer cells to ensure their fast proliferation, and to cancer related byproducts such as $\mathrm{H}_{2} \mathrm{O}_{2}$ [144]. Yang et al. fabricated an electrochemical biosensor based on reduced graphene oxide quantum dots ( $\mathrm{rGO} Q \mathrm{QDs}$ )/ $\mathrm{ZnO}$ hybrid nanofibers, for the detection of $\mathrm{H}_{2} \mathrm{O}_{2}$ released from cancer and normal cells, under the stimuli of anticancer drugs [145]. The authors demonstrated the ability of the system to quantify the amount of $\mathrm{H}_{2} \mathrm{O}_{2}$ released from a prostate cancer cell (PC-3) and healthy cells (BPH-1) under the stimuli of the anticancer drugs apigenin and with the antisense CK2a oligonucleotide. Wang et al. explored an electrocatalyst for the sensitive and specific detection of extracellular $\mathrm{H}_{2} \mathrm{O}_{2}$ released from living cancer cells, based on Pd nanoparticles decorated double shell structured N-doped GQDs@N-doped carbon (NC) hollow nanospheres (HNSs), for the sensitive and specific detection of extracellular $\mathrm{H}_{2} \mathrm{O}_{2}$ released from living cancer cells [115]. In this work, N-GQDs synthesized from the carbonization of citric acid, were wrapped on amino-functionalized $\mathrm{SiO}_{2}$ nanospheres through electrostatic and hydrogen bonds interactions and coated with polydopamine (PDA) via self-polymerization of dopamine 
hydrochloride on their surface. The subsequent decoration with Pd NPs followed by carbonization under inert atmosphere and etching of $\mathrm{SiO}_{2}$ cores with $\mathrm{HF}$ solution, allowed to obtain the sensing substrate NGQD@NC@Pd HNSs. This hybrid material demonstrated high electrocatalytic activity toward the electrochemical reduction of $\mathrm{H}_{2} \mathrm{O}_{2}$ with short response time (within $2 \mathrm{~s}$ ) at the favorable potential of $0 \mathrm{~V}$ and with a low LOD $(20 \mathrm{nM})$. The biosensor was successfully investigated for the real-time tracking of trace amounts of $\mathrm{H}_{2} \mathrm{O}_{2}$ secreted from different human living cells (MDA-MB-231 and HBL-100) and of the U87 cancer cell line. An ultrasensitive electrochemical biosensor based on multiple layer CdS QDs functionalized polystyrene microspheres (PS) as bioprobe and (GO)-polyaniline (PANI) as capture electrode, was developed by Wang et al. for the detection of K562 cell, a human immortalized myelogenous leukemia cell line [146]. The biosensor showed a low LOD of 3 cells mL $\mathrm{mL}^{-1}$ and a wide linear range $\left(10-1.0 \times 10^{7}\right.$ cells $\left.\mathrm{mL}^{-1}\right)$, and was also successfully tested for mannosyl groups on HeLa cells and Hct116 cells, showing high specificity and sensitivity.

Aberrant glycan epitopes are a classic hallmark of cancer and can be used to recognize and detect different kind of tumors [147]. Yu et al. reported an ultrasensitive photoelectrochemical biosensor for the N-glycan expression based on GQDs, synthesized by chemical oxidation from carbon black, nanogold-assembled mesoporous silica nanoparticles (GM$\mathrm{SNs}$ ) and combined with multibranched hybridization chain reaction (mHCR) [116]. In this study, GQDs were conjugated with concanavalin A (ConA), a carbohydrate-binding protein able to recognize $\mathrm{N}$-glycan expressed on the cancer cell surface. Porous $\mathrm{ZnO}$ spheres were covered on the paper working electrode with Au nanorod (Au-PWE) and with CdTe QDs and subsequently with GMSNs; then, the HRP labeled DNA with multiple branched arms (HRP-mdhDNA) was covalently linked with the ethanediamine treated GMSNs through the formation of amide bond with the carboxyl group of the enzyme. The analytical principle of this biosensor is depicted in Figure 7. The chemiluminescent (CL) emission of this luminol-HRP- $\mathrm{H}_{2} \mathrm{O}_{2}$ system used HPR as inner light source able to excite the photoactive materials. Under the light source, $\mathrm{ZnO}$ sensitized by CdTe QDs and with the aid of the localized surface plasmon resonance of GMSNs, gave photocurrent response. The interaction of ConA-GQDs with the cancer cells competitively absorbed the $\mathrm{CL}$, producing a weakening in the photocurrent intensity. The authors reported that, when compared with control tests, the biosensor showed greater ability to evaluate $\mathrm{N}$-glycan expression of the cancer cells surface with high sensitivity and with a LOD of 21 cells per mL.
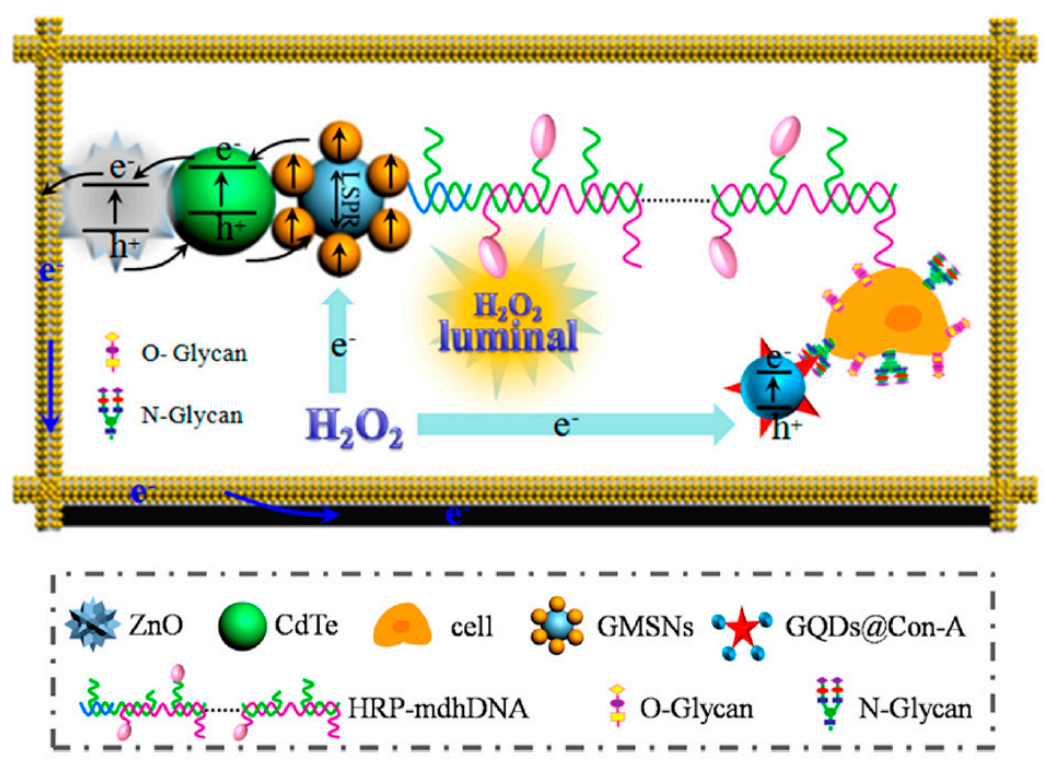

Figure 7. Analytical principle of photoelectrochemical biosensor based on ConA-GQDs. Reprinted with permission from ACS Applied Materials \& Interfaces, ref. [116]. Copyright (2017) American Chemical Society. 
A "turn-on" magnetic fluorescent biosensor based on N,S/GQDs $\mathrm{Fe}_{3} \mathrm{O}_{4}$, and $\mathrm{MoS}_{2}$ nanosheets for the rapid and sensitive detection of circulating tumor cells was reported by Cui et al. [117]. In this study, the photoluminescent GQDs with an average diameter of $5 \mathrm{~nm}$ were synthesized by electrolysis of graphite rods using a solution of sodium p-toluenesulfonate. The nanomaterials were conjugated via EDC/Sulfo-NHS chemistry with a complex constituted by the magnetic agent $\mathrm{Fe}_{3} \mathrm{O}_{4}$ and a functional aptamer able to target the epithelial cell adhesion molecule (EpCAM). The system was coupled with $\mathrm{MoS}_{2}$ nanosheets, which acted in this system as fluorescence quenchers. This "turn-on" magnetic fluorescent nanocomposite was investigated in different cultures of low- and high-EpCAM-expressing cancer cell lines (Hep G2, A549, HEK293), showing a specific ability to quickly identify CTCs (both low- and high-EpCAM-expressing cells), because of the presence of aptamers, with a linear range between 2 and $64 \mathrm{nM}$, and a LOD of $1.19 \mathrm{nM}$, thus highlighting its potential for the for early diagnosis and prognosis of cancer.

\section{Conclusions and Future Remarks}

The best chance to reduce cancer deaths and to increase the chances of treatment success is the early detection of cancer, possibly in the site of origin, before it invades the surrounding tissues and distant organs. The currently used molecular-based assays for the routine diagnosis of cancer, generally suffer from low sensitivity, time-consuming processes and the impossibility to allow the on-site detection, in biological media. The advances of nanotechnology in biosensing field has demonstrated great promises in revolutionizing cancer diagnostics, by empowering miniaturized biosensors for the effective on-site early diagnosis of cancer. Among the differently investigated nano-sized substrates for the detection of cancer biomarkers, the zero dimensional GQDs, showed great promises due to their remarkable electronic and optical properties, their large surface area and the presence of different active sites for the chemical functionalization. Their covalent bonding with biomolecules able to recognize cancer biomarkers or to detect tumor cells, have shown to afford advanced sensing substrates for the fast and accurate point of care cancer diagnosis and the monitoring of treatment progression.

In this review, we have discussed different strategies involving the synthesis and functionalization of GQDs with different biomolecules able to recognize and convert into a signal, specific cancer biomarkers such as antigens, enzymes, hormones, proteins, cancer related byproducts, biomolecules exposed on the surface of cancer cells and also changes in $\mathrm{pH}$. The developed biosensors have shown to ensure the effective diagnosis and monitoring of cancer diseases as well as the possibility to evaluate the effectiveness of anticancer therapy, thus suggesting their great potential in clinics for the diagnosis and management of cancer. However, despite the outstanding performances of the developed biosensors, the future research in this field will of course take into account the need to move biosensors into point of care systems for the detection of multiple cancer biomarkers. The devices should be sensitive, rapid, easy to use, also ensuring the accuracy and reliability of the laboratory.

The major challenge in using GQDs for the fabrication of sensing devices is the largescale synthesis of high-quality and stable nanoparticles, with definite size, shapes, charge and agglomeration state, since these features have a great impact on the physicochemical properties of these nanomaterials and thus, on the GQDs based sensors performance. The outstanding results obtained in the use of these nanomaterials for immunosensing still require more studies in order to compare the obtained results with other existing techniques. The excellent chemical, physical and optical properties of GQDs will allow many application in biosensing field. However, new protocols for the detection of cancer biomarkers and cancer cells are needed for these highly sensitive immunosensors. We believe that the use of a multidisciplinary approach that combines knowledge in biology, physics, chemistry and engineering, will certainly guarantee the possibility, in the next future, to develop smart biosensors able to provide the easy, fast and accurate early diagnosis of cancer, thus increasing the patients' survival rates. 


\begin{abstract}
Author Contributions: For articles with several authors, the following statements should be used “Conceptualization, D.I., C.E. and G.N.; methodology, D.I. and C.C.; software, C.C. and A.F.; validation, C.E. and G.N.; formal analysis, A.F.; investigation, D.I.; resources, G.N.; data curation, D.I. and C.C.; writing-original draft preparation, D.I.; writing-review and editing, D.I., C.C. and G.N.; visualization, C.E.; supervision, D.I. and G.N.; project administration, D.I. and C.E.; funding acquisition, C.E. All authors have read and agreed to the published version of the manuscript.
\end{abstract}

Funding: This research received no external funding.

Conflicts of Interest: The authors declare no conflict of interest.

\title{
References
}

1. Bray, F.; Ferlay, J.; Soerjomataram, I.; Siegel, R.L.; Torre, L.A.; Jemal, A. Global cancer statistics 2018: GLOBOCAN estimates of incidence and mortality worldwide for 36 cancers in 185 countries. CA Cancer J. Clin. 2018, 68, 394-424. [CrossRef] [PubMed]

2. Ramadan, S.; Lobo, R.; Zhang, Y.; Xu, L.; Shaforost, O.; Kwong, H.; Tsang, D.; Feng, J.; Yin, T.; Qiao, M.; et al. Carbon-DotEnhanced Graphene Field-Effect Transistors for Ultrasensitive Detection of Exosomes. ACS Appl. Mater. Interfaces 2021, 13, 7854-7864. [CrossRef] [PubMed]

3. Falzone, L.; Salomone, S.; Libra, M. Evolution of cancer pharmacological treatments at the turn of the third millennium. Front. Pharmacol. 2018, 9, 1300. [CrossRef] [PubMed]

4. Mahato, K.; Kumar, A.; Maurya, P.K.; Chandra, P. Shifting paradigm of cancer diagnoses in clinically relevant samples based on miniaturized electrochemical nanobiosensors and microfluidic devices. Biosens. Bioelectron. 2018, 100, 411-428. [CrossRef]

5. Wu, M.; Shu, J. Multimodal Molecular Imaging: Current Status and Future Directions. Contrast Media Mol. Imaging 2018, 2018, 1382183. [CrossRef]

6. Kumar, S. Noninvasive Nanodiagnostics for Cancer. Cancer Biomarkers; CRC Press: Boca Raton, FL, USA, 2013; pp. 85-94. [CrossRef]

7. Afreen, S.; He, Z.; Xiao, Y.; Zhu, J.J. Nanoscale metal-organic frameworks in detecting cancer biomarkers. J. Mater. Chem. B 2020, 8, 1338-1349. [CrossRef]

8. Chauhan, N.; Maekawa, T.; Kumar, D.N.S. Graphene based biosensors-Accelerating medical diagnostics to new-dimensions. J. Mater. Res. 2017, 32, 2860-2882. [CrossRef]

9. Sharifi, M.; Avadi, M.R.; Attar, F.; Dashtestani, F.; Ghorchian, H.; Rezayat, S.M.; Saboury, A.A.; Falahati, M. Cancer diagnosis using nanomaterials based electrochemical nanobiosensors. Biosens. Bioelectron. 2019, 126, 773-784. [CrossRef] [PubMed]

10. Pirzada, M.; Altintas, Z. Nanomaterials for Healthcare. Sensors 2019, 19, 5311. [CrossRef]

11. Biju, V. Chemical modifications and bioconjugate reactions of nanomaterials for sensing, imaging, drug delivery and therapy. Chem. Soc. Rev. 2014, 43, 744-764. [CrossRef]

12. Zeng, W.; Wang, H.; Li, Z. Nanomaterials for Sensing Applications. J. Nanotechnol. 2016, 2016, 2083948. [CrossRef]

13. Holzinger, M.; Goff, A.L.; Cosnier, S. Nanomaterials for biosensing applications: A review. Front. Chem. 2014, 2, 63. [CrossRef]

14. Suvarnaphaet, P.; Pechprasarn, S. Graphene-based materials for biosensors: A review. Sensors 2017, 17, 2161. [CrossRef]

15. Baldo, S.; Buccheri, S.; Ballo, A.; Camarda, M.; La Magna, A.; Castagna, M.E.; Romano, A.; Iannazzo, D.; Di Raimondo, F.; Neri, G.; et al. Carbon nanotube-based sensing devices for human Arginase-1 detection. Sens. Bio Sens. Res. 2016, 7, 168-173. [CrossRef]

16. Song, Y.; Luo, Y.; Zhu, C.; Li, H.; Du, D.; Lin, Y. Recent advances in electrochemical biosensors based on graphene two-dimensional nanomaterials. Biosens. Bioelectron. 2016, 76, 195-212. [CrossRef]

17. Krishnan, S.K.; Singh, E.; Singh, P.; Meyyappan, M.; Nalwa, H.S. A review on graphene-based nanocomposites for electrochemical and fluorescent biosensors. RSC Adv. 2019, 9, 8778-8781. [CrossRef]

18. Yang, M.; Javadi, A.; Gong, S. Sensitive electrochemical immunosensor for the detection of cancer biomarker using quantum dot functionalized graphene sheets as labels. Sens. Actuators B Chem. 2011, 155, 357-360. [CrossRef]

19. Iannazzo, D.; Pistone, A.; Galvagno, S.; Ferro, S.; De Luca, L.; Monforte, A.M.; Da Ros, T.; Hadad, C.; Prato, M.; Pannecouque, C. Synthesis and anti-HIV activity of carboxylated and drug-conjugated multi-walled carbon nanotubes. Carbon N. Y. 2015, 82, 548-561. [CrossRef]

20. Pistone, A.; Iannazzo, D.; Ansari, S.; Milone, C.; Salamò, M.; Galvagno, S.; Cirmi, S.; Navarra, M. Tunable doxorubicin release from polymer-gated multiwalled carbon nanotubes. Int. J. Pharm. 2016, 515, 30-36. [CrossRef]

21. Iannazzo, D.; Pistone, A.; Galvagno, S. Functionalization methods of graphene. In Functionalization of Carbon Nanomaterials: Chemistry and Applications; Thakur, V.K., Thakur, M.K., Eds.; Chemical; CRC Press: Boca Raton, FL, USA, 2015 ; pp. 510-537.

22. Yan, Y.; Gong, J.; Chen, J.; Zeng, Z.; Huang, W.; Pu, K.; Liu, J.; Chen, P. Recent Advances on Graphene Quantum Dots: From Chemistry and Physics to Applications. Adv. Mater. 2019, 31, 1808283. [CrossRef]

23. Iannazzo, D.; Ziccarelli, I.; Pistone, A. Graphene quantum dots: Multifunctional nanoplatforms for anticancer therapy. J. Mater. Chem. B 2017, 5, 6471-6489. [CrossRef]

24. Iannazzo, D.; Celesti, C.; Espro, C. Recent Advances on Graphene Quantum Dots as Multifunctional Nanoplatforms for Cancer Treatment. Biotechnol. J. 2021, 16, 1900422. [CrossRef] [PubMed]

25. Iannazzo, D.; Ettari, R.; Giofrè, S.; Eid, A.H.; Bitto, A. Recent advances in nanotherapeutics for multiple myeloma. Cancers 2020, 12, 3144. [CrossRef] [PubMed] 
26. Jin, S.H.; Kim, D.H.; Jun, G.H.; Hong, S.H.; Jeon, S. Tuning the photoluminescence of graphene quantum dots through the charge transfer effect of functional groups. ACS Nano 2013, 7, 1239-1245. [CrossRef] [PubMed]

27. Giofrè, S.V.; Tiecco, M.; Celesti, C.; Patanè, S.; Triolo, C.; Gulino, A.; Spitaleri, L.; Scalese, S.; Scuderi, M.; Iannazzo, D. Eco-friendly 1,3-dipolar cycloaddition reactions on graphene quantum dots in natural deep eutectic solvent. Nanomaterials 2020, 10, 2549. [CrossRef] [PubMed]

28. Javanbakht, S.; Namazi, H. Doxorubicin Loaded Carboxymethyl Cellulose/Graphene Quantum dot Nanocomposite Hydrogel Films as a Potential Anticancer Drug Delivery System; Elsevier B.V.: Amsterdam, The Netherlands, 2018; Volume 87, ISBN 4133340191.

29. Dong, J.; Wang, K.; Sun, L.; Sun, B.; Yang, M.; Chen, H.; Wang, Y.; Sun, J.; Dong, L. Application of graphene quantum dots for simultaneous fluorescence imaging and tumor-targeted drug delivery. Sens. Actuators B Chem. 2018, 256, 616-623. [CrossRef]

30. Mansuriya, B.D.; Altintas, Z. Applications of graphene quantum dots in biomedical sensors. Sensors 2020, 20, 1072. [CrossRef] [PubMed]

31. Pirsaheb, M.; Mohammadi, S.; Salimi, A. Current advances of carbon dots based biosensors for tumor marker detection, cancer cells analysis and bioimaging. TrAC Trends Anal. Chem. 2019, 115, 83-99. [CrossRef]

32. Lim, C.S.; Hola, K.; Ambrosi, A.; Zboril, R.; Pumera, M. Graphene and carbon quantum dots electrochemistry. Electrochem. Commun. 2015, 52, 75-79. [CrossRef]

33. Tian, P.; Tang, L.; Teng, K.S.; Lau, S.P. Graphene quantum dots from chemistry to applications. Mater. Today Chem. 2018, 10, 221-258. [CrossRef]

34. Wang, Y.; Zhu, Y.; Yu, S.; Jiang, C. Fluorescent carbon dots: Rational synthesis, tunable optical properties and analytical applications. RSC Adv. 2017, 7, 40973-40989. [CrossRef]

35. Kim, S.; Hwang, S.W.; Kim, M.K.; Shin, D.Y.; Shin, D.H.; Kim, C.O.; Yang, S.B.; Park, J.H.; Hwang, E.; Choi, S.H.; et al. Anomalous behaviors of visible luminescence from graphene quantum dots: Interplay between size and shape. ACS Nano 2012, 6, 8203-8208. [CrossRef]

36. Li, L.; Wu, G.; Yang, G.; Peng, J.; Zhao, J.; Zhu, J.J. Focusing on luminescent graphene quantum dots: Current status and future perspectives. Nanoscale 2013, 5, 4015-4039. [CrossRef] [PubMed]

37. Zhu, S.; Zhang, J.; Tang, S.; Qiao, C.; Wang, L.; Wang, H.; Liu, X.; Li, B.; Li, Y.; Yu, W.; et al. Surface chemistry routes to modulate the photoluminescence of graphene quantum dots: From fluorescence mechanism to up-conversion bioimaging applications. Adv. Funct. Mater. 2012, 22, 4732-4740. [CrossRef]

38. Yang, S.; Sun, J.; Zhu, C.; He, P.; Peng, Z.; Ding, G. Supramolecular recognition control of polyethylene glycol modified Ndoped graphene quantum dots: Tunable selectivity for alkali and alkaline-earth metal ions. J. Mater. Chem. C 2015, 3, 10715-10722 [CrossRef]

39. Kalkal, A.; Pradhan, R.; Kadian, S.; Manik, G.; Packirisamy, G. Biofunctionalized Graphene Quantum Dots Based Fluorescent Biosensor toward Efficient Detection of Small Cell Lung Cancer. ACS Appl. Biol. Mater. 2020, 3, 4922-4932. [CrossRef]

40. Mansuriya, B.D.; Altintas, Z. Graphene quantum dot-based electrochemical immunosensors for biomedical applications. Materials 2020, 13, 96. [CrossRef]

41. Sun, H.; Wu, L.; Wei, W.; Qu, X. Recent advances in graphene quantum dots for sensing. Mater. Today 2013, 16, 433-442. [CrossRef]

42. Faridbod, F.; Sanati, A.L. Graphene Quantum Dots in Electrochemical Sensors/Biosensors. Curr. Anal. Chem. 2018, 15, 103-123. [CrossRef]

43. Bressi, V.; Ferlazzo, A.; Iannazzo, D.; Espro, C. Graphene quantum dots by eco-friendly green synthesis for electrochemical sensing: Recent advances and future perspectives. Nanomaterials 2021, 11, 1120. [CrossRef]

44. Kumar, Y.R.; Deshmukh, K.; Sadasivuni, K.K.; Pasha, S.K.K. Graphene quantum dot based materials for sensing, bio-imaging and energy storage applications: A review. RSC Adv. 2020, 10, 23861-23898. [CrossRef]

45. Kellici, S.; Acord, J.; Power, N.P.; Morgan, D.J.; Coppo, P.; Heil, T.; Saha, B. Rapid synthesis of graphene quantum dots using a continuous hydrothermal flow synthesis approach. RSC Adv. 2017, 7, 14716-14720. [CrossRef]

46. Kang, S.; Jeong, Y.K.; Jung, K.H.; Son, Y.; Choi, S.C.; An, G.S.; Han, H.; Kim, K.M. Simple preparation of graphene quantum dots with controllable surface states from graphite. RSC Adv. 2019, 9, 38447-38453. [CrossRef]

47. Dong, S.; Bi, Q.; Qiao, C.; Sun, Y.; Zhang, X.; Lu, X.; Zhao, L. Electrochemical sensor for discrimination tyrosine enantiomers using graphene quantum dots and $\beta$-cyclodextrins composites. Talanta 2017, 173, 94-100. [CrossRef] [PubMed]

48. Wang, B.; Zhuo, S.; Chen, L.; Zhang, Y. Fluorescent graphene quantum dot nanoprobes for the sensitive and selective detection of mercury ions. Spectrochim. Acta Part A Mol. Biomol. Spectrosc. 2014, 131, 384-387. [CrossRef] [PubMed]

49. Tang, D.; Liu, J.; Yan, X.; Kang, L. Graphene oxide derived graphene quantum dots with different photoluminescence properties and peroxidase-like catalytic activity. RSC Adv. 2016, 6, 50609-50617. [CrossRef]

50. Tian, R.; Zhong, S.; Wu, J.; Jiang, W.; Wang, T. Facile hydrothermal method to prepare graphene quantum dots from graphene oxide with different photoluminescences. RSC Adv. 2016, 6, 40422-40426. [CrossRef]

51. Teymourinia, H.; Salavati-Niasari, M.; Amiri, O.; Farangi, M. Facile synthesis of graphene quantum dots from corn powder and their application as down conversion effect in quantum dot-dye-sensitized solar cell. J. Mol. Liq. 2018, 251, 267-272. [CrossRef]

52. Chen, W.; Shen, J.; Lv, G.; Li, D.; Hu, Y.; Zhou, C.; Liu, X.; Dai, Z. Green Synthesis of Graphene Quantum Dots from Cotton Cellulose. Chem. Select 2019, 4, 2898-2902. [CrossRef]

53. Wang, W.; Wang, Z.; Liu, J.; Peng, Y.; Yu, X.; Wang, W.; Zhang, Z.; Sun, L. One-Pot Facile Synthesis of Graphene Quantum Dots from Rice Husks for Fe3+ Sensing. Ind. Eng. Chem. Res. 2018, 57, 9144-9150. [CrossRef] 
54. Liu, F.; Jang, M.H.; Ha, H.D.; Kim, J.H.; Cho, Y.H.; Seo, T.S. Facile synthetic method for pristine graphene quantum dots and graphene oxide quantum dots: Origin of blue and green luminescence. Adv. Mater. 2013, 25, 3657-3662. [CrossRef] [PubMed]

55. Gu, S.; Hsieh, C.T.; Chiang, Y.M.; Tzou, D.Y.; Chen, Y.F.; Gandomi, Y.A. Optimization of Graphene Quantum Dots by Chemical Exfoliation from Graphite Powders and Carbon Nanotubes; Elsevier B.V.: Amsterdam, The Netherlands, 2018; Volume 215, ISBN 8863455937.

56. Sarkar, S.; Gandla, D.; Venkatesh, Y.; Bangal, P.R.; Ghosh, S.; Yang, Y.; Misra, S. Graphene quantum dots from graphite by liquid exfoliation showing excitation-independent emission, fluorescence upconversion and delayed fluorescence. Phys. Chem. Chem. Phys. 2016, 18, 21278-21287. [CrossRef] [PubMed]

57. Zdrazil, L.; Zahradnicek, R.; Mohan, R.; Sedlacek, P.; Nejdl, L.; Schmiedova, V.; Pospisil, J.; Horak, M.; Weiter, M.; Zmeskal, O.; et al. Preparation of graphene quantum dots through liquid phase exfoliation method. J. Lumin. 2018, 204, 203-208. [CrossRef]

58. Fu, Y.; Liu, R.; Zhi, J. Facile synthesis of graphene quantum dots based on electrochemical method and their application for specific Fe3+ detection. Adv. Mater. Lett. 2018, 9, 614-618. [CrossRef]

59. Peng, J.; Zhao, Z.; Zheng, M.; Su, B.; Chen, X.; Chen, X. Electrochemical synthesis of phosphorus and sulfur co-doped graphene quantum dots as efficient electrochemiluminescent immunomarkers for monitoring okadaic acid. Sens. Actuators B Chem. 2020, 304, 127383. [CrossRef]

60. Joffrion, J.B.; Clower, W.; Wilson, C.G. Tunable excitation-independent emissions from graphene quantum dots through microplasma-assisted electrochemical synthesis. Nano Struct. Nano Objects 2019, 19, 100341. [CrossRef]

61. Kalita, H.; Palaparthy, V.S.; Baghini, M.S.; Aslam, M. Electrochemical synthesis of graphene quantum dots from graphene oxide at room temperature and its soil moisture sensing properties. Carbon N. Y. 2020, 165, 9-17. [CrossRef]

62. Nirala, N.R.; Khandelwal, G.; Kumar, B.; Vinita; Prakash, R.; Kumar, V. One step electro-oxidative preparation of graphene quantum dots from wood charcoal as a peroxidase mimetic. Talanta 2017, 173, 36-43. [CrossRef]

63. Wang, L.; Wang, Y.; Xu, T.; Liao, H.; Yao, C.; Liu, Y.; Li, Z.; Chen, Z.; Pan, D.; Sun, L.; et al. Gram-scale synthesis of single-crystalline graphene quantum dots with superior optical properties. Nat. Commun. 2014, 5, 5357. [CrossRef]

64. Fan, Z.; Nie, Y.; Wei, Y.; Zhao, J.; Liao, X.; Zhang, J. Facile and large-scale synthesis of graphene quantum dots for selective targeting and imaging of cell nucleus and mitochondria. Mater. Sci. Eng. C 2019, 103, 109824. [CrossRef]

65. Ge, S.; He, J.; Ma, C.; Liu, J.; Xi, F.; Dong, X. One-step synthesis of boron-doped graphene quantum dots for fluorescent sensors and biosensor. Talanta 2019, 199, 581-589. [CrossRef]

66. Tam, T.V.; Hong, S.H.; Choi, W.M. Facile synthesis of cysteine-functionalized graphene quantum dots for a fluorescence probe for mercury ions. RSC Adv. 2015, 5, 97598-97603. [CrossRef]

67. More, M.P.; Lohar, P.H.; Patil, A.G.; Patil, P.O.; Deshmukh, P.K. Controlled synthesis of blue luminescent graphene quantum dots from carbonized citric acid: Assessment of methodology, stability, and fluorescence in an aqueous environment. Mater. Chem. Phys. 2018, 220, 11-22. [CrossRef]

68. Bayat, A.; Saievar-Iranizad, E. Synthesis of green-photoluminescent single layer graphene quantum dots: Determination of HOMO and LUMO energy states. J. Lumin. 2017, 192, 180-183. [CrossRef]

69. Wadhwa, S.; John, A.T.; Mathur, A.; Khanuja, M.; Bhattacharya, G.; Roy, S.S.; Ray, S.C. Engineering of luminescent graphene quantum dot-gold (GQD-Au) hybrid nanoparticles for functional applications. MethodsX 2020, 7, 100963. [CrossRef] [PubMed]

70. Chen, W.; Li, D.; Tian, L.; Xiang, W.; Wang, T.; Hu, W.; Hu, Y.; Chen, S.; Chen, J.; Dai, Z. Synthesis of graphene quantum dots from natural polymer starch for cell imaging. Green Chem. 2018, 20, 4438-4442. [CrossRef]

71. Fresco-Cala, B.; Soriano, M.L.; Sciortino, A.; Cannas, M.; Messina, F.; Cardenas, S. One-pot synthesis of graphene quantum dots and simultaneous nanostructured self-assembly: Via a novel microwave-assisted method: Impact on triazine removal and efficiency monitoring. RSC Adv. 2018, 8, 29939-29946. [CrossRef]

72. Li, R.; Liu, Y.; Li, Z.; Shen, J.; Yang, Y.; Cui, X.; Yang, G. Bottom-Up Fabrication of Single-Layered Nitrogen-Doped Graphene Quantum Dots through Intermolecular Carbonization Arrayed in a 2D Plane. Chem. A Eur. J. 2016, 22, 272-278. [CrossRef]

73. Liu, R.; Wu, D.; Feng, X.; Müllen, K. Bottom-up fabrication of photoluminescent graphene quantum dots with uniform morphology. J. Am. Chem. Soc. 2011, 133, 15221-15223. [CrossRef]

74. Gao, S.; Tang, L.; Xiang, J.; Ji, R.; Lai, S.K.; Yuan, S.; Lau, S.P. Facile preparation of sulphur-doped graphene quantum dots for ultra-high performance ultraviolet photodetectors. New J. Chem. 2017, 41, 10447-10451. [CrossRef]

75. Bagheri, Z.; Ehtesabi, H.; Rahmandoust, M.; Ahadian, M.M.; Hallaji, Z.; Eskandari, F.; Jokar, E. New insight into the concept of carbonization degree in synthesis of carbon dots to achieve facile smartphone based sensing platform. Sci. Rep. 2017, 7, 11013. [CrossRef] [PubMed]

76. Wu, X.; Tian, F.; Wang, W.; Chen, J.; Wu, M.; Zhao, J.X. Fabrication of highly fluorescent graphene quantum dots using L-glutamic acid for in vitro/in vivo imaging and sensing. J. Mater. Chem. C 2013, 1, 4676-4684. [CrossRef]

77. Naik, J.P.; Sutradhar, P.; Saha, M. Molecular scale rapid synthesis of graphene quantum dots (GQDs). J. Nanostruct. Chem. 2017, 7, 85-89. [CrossRef]

78. Hong, G.L.; Zhao, H.L.; Deng, H.H.; Yang, H.J.; Peng, H.P.; Liu, Y.H.; Chen, W. Fabrication of ultra-small monolayer graphene quantum dots by pyrolysis of trisodium citrate for fluorescent cell imaging. Int. J. Nanomed. 2018, 13, 4807-4815. [CrossRef]

79. Zhu, J.; Tang, Y.; Wang, G.; Mao, J.; Liu, Z.; Sun, T.; Wang, M.; Chen, D.; Yang, Y.; Li, J.; et al. Green, Rapid, and Universal Preparation Approach of Graphene Quantum Dots under Ultraviolet Irradiation. ACS Appl. Mater. Interfaces 2017, 9, 14470-14477. [CrossRef] 
80. Veeresh, S.; Ganesh, H.; Nagaraj, Y.S.; Vandana, M.; Ashokkumar, S.P.; Yesappa, L.; Vijeth, H.; Devendrappa, H. UV-irradiation induced synthesis of reduced graphene quantum dots. Mater. Today Proc. 2020, 45, 3968-3970. [CrossRef]

81. Shen, J.; Zhu, Y.; Yang, X.; Li, C. Graphene quantum dots: Emergent nanolights for bioimaging, sensors, catalysis and photovoltaic devices. Chem. Commun. 2012, 48, 3686-3699. [CrossRef]

82. Iannazzo, D.; Pistone, A.; Ferro, S.; De Luca, L.; Monforte, A.M.; Romeo, R.; Buemi, M.R.; Pannecouque, C. Graphene Quantum Dots Based Systems As HIV Inhibitors. Bioconjug. Chem. 2018, 29, 3084-3093. [CrossRef]

83. Fei, X.; Liu, Z.; Li, Y.; Yang, G.; Su, C.; Zhong, H.; Zhuang, Z.; Guo, Z. One-pot green synthesis of fl ower-liked Au NP @ GQDs nanocomposites for surface-enhanced Raman scattering. J. Alloys Compd. 2017, 725, 1084-1090. [CrossRef]

84. Le, T.H.; Oh, Y.; Kim, H.; Yoon, H. Exfoliation of 2D Materials for Energy and Environmental Applications. Chem. A Eur. J. 2020, 26, 6360-6401. [CrossRef]

85. Wei, S.; Zhang, R.; Liu, Y.; Ding, H.; Zhang, Y.L. Graphene quantum dots prepared from chemical exfoliation of multiwall carbon nanotubes: An efficient photocatalyst promoter. Catal. Commun. 2016, 74, 104-109. [CrossRef]

86. Sapkota, B.; Benabbas, A.; Lin, H.Y.G.; Liang, W.; Champion, P.; Wanunu, M. Peptide-Decorated Tunable-Fluorescence Graphene Quantum Dots. ACS Appl. Mater. Interfaces 2017, 9, 9378-9387. [CrossRef]

87. Peng, J.; Gao, W.; Gupta, B.K.; Liu, Z.; Romero-Aburto, R.; Ge, L.; Song, L.; Alemany, L.B.; Zhan, X.; Gao, G.; et al. Graphene quantum dots derived from carbon fibers. Nano Lett. 2012, 12, 844-849. [CrossRef]

88. Ahirwar, S.; Mallick, S.; Bahadur, D. Electrochemical Method to Prepare Graphene Quantum Dots and Graphene Oxide Quantum Dots. ACS Omega 2017, 2, 8343-8353. [CrossRef]

89. Tajik, S.; Dourandish, Z.; Zhang, K.; Beitollahi, H.; Le, Q.V.; Jang, H.W.; Shokouhimehr, M. Carbon and graphene quantum dots: A review on syntheses, characterization, biological and sensing applications for neurotransmitter determination. RSC Adv. 2020, 10, 15406-15429. [CrossRef]

90. Hoang, T.T.; Pham, H.P.; Tran, Q.T. A Facile Microwave-Assisted Hydrothermal Synthesis of Graphene Quantum Dots for Organic Solar Cell Efficiency Improvement. J. Nanomater. 2020, 2020, 15-17. [CrossRef]

91. Do, S.; Kwon, W.; Rhee, S.W. Soft-template synthesis of nitrogen-doped carbon nanodots: Tunable visible-light photoluminescence and phosphor-based light-emitting diodes. J. Mater. Chem. C 2014, 2, 4221-4226. [CrossRef]

92. Wang, L.; Li, W.; Wu, B.; Li, Z.; Pan, D.; Wu, M. Room-temperature synthesis of graphene quantum dots via electron-beam irradiation and their application in cell imaging. Chem. Eng. J. 2017, 309, 374-380. [CrossRef]

93. Wu, L.; Qu, X. Cancer biomarker detection: Recent achievements and challenges. Chem. Soc. Rev. 2015, 44, 2963-2997. [CrossRef]

94. Kumawat, M.K.; Thakur, M.; Gurung, R.B.; Srivastava, R. Graphene Quantum Dots for Cell Proliferation, Nucleus Imaging, and Photoluminescent Sensing Applications. Sci. Rep. 2017, 7, 15858. [CrossRef] [PubMed]

95. Fan, Z.; Zhou, S.; Garcia, C.; Fan, L.; Zhou, J. PH-Responsive fluorescent graphene quantum dots for fluorescence-guided cancer surgery and diagnosis. Nanoscale 2017, 9, 4928-4933. [CrossRef] [PubMed]

96. Li, N.; Than, A.; Chen, J.; Xi, F.; Liu, J.; Chen, P. Graphene quantum dots based fluorescence turn-on nanoprobe for highly sensitive and selective imaging of hydrogen sulfide in living cells. Biomater. Sci. 2018, 6, 779-784. [CrossRef] [PubMed]

97. Guo, R.; Zhou, S.; Li, Y.; Li, X.; Fan, L.; Voelcker, N.H. Rhodamine-Functionalized Graphene Quantum Dots for Detection of Fe3+ in Cancer Stem Cells. ACS Appl. Mater. Interfaces 2015, 7, 23958-23966. [CrossRef]

98. Ogaidi, I.A.; Gou, H.; Aguilar, Z.P.; Guo, S.; Melconian, A.K.; Al-Kazaz, A.K.A.; Meng, F.; Wu, N. Detection of the ovarian cancer biomarker CA-125 using chemiluminescence resonance energy transfer to graphene quantum dots. Chem. Commun. 2014, 50, 1344-1346. [CrossRef] [PubMed]

99. Saadati, A.; Hassanpour, S.; Bahavarnia, F.; Hasanzadeh, M. A novel biosensor for the monitoring of ovarian cancer tumor protein CA 125 in untreated human plasma samples using a novel nano-ink: A new platform for efficient diagnosis of cancer using paper based microfluidic technology. Anal. Methods 2020, 12, 1639-1649. [CrossRef]

100. Yang, Y.; Liu, Q.; Liu, Y.; Cui, J.; Liu, H.; Wang, P.; Li, Y.; Chen, L.; Zhao, Z.; Dong, Y. A novel label-free electrochemical immunosensor based on functionalized nitrogen-doped graphene quantum dots for carcinoembryonic antigen detection. Biosens. Bioelectron. 2017, 90, 31-38. [CrossRef]

101. Nie, G.; Wang, Y.; Tang, Y.; Zhao, D.; Guo, Q. A graphene quantum dots based electrochemiluminescence immunosensor for carcinoembryonic antigen detection using poly(5-formylindole)/reduced graphene oxide nanocomposite. Biosens. Bioelectron. 2018, 101, 123-128. [CrossRef]

102. Ganganboina, A.B.; Doong, R.A. Graphene Quantum Dots Decorated Gold-Polyaniline Nanowire for Impedimetric Detection of Carcinoembryonic Antigen. Sci. Rep. 2019, 9, 7214. [CrossRef]

103. Hasanzadeh, M.; Tagi, S.; Solhi, E.; Mokhtarzadeh, A.; Shadjou, N.; Eftekhari, A.; Mahboob, S. An innovative immunosensor for ultrasensitive detection of breast cancer specific carbohydrate (CA 15-3) in unprocessed human plasma and MCF-7 breast cancer cell lysates using gold nanospear electrochemically assembled onto thiolated graphene quantum dots. Int. J. Biol. Macromol. 2018, 114, 1008-1017. [CrossRef]

104. Hasanzadeh, M.; Baghban, H.N.; Shadjou, N.; Mokhtarzadeh, A. Ultrasensitive electrochemical immunosensing of tumor suppressor protein $\mathrm{p} 53$ in unprocessed human plasma and cell lysates using a novel nanocomposite based on poly-cysteine/graphene quantum dots/gold nanoparticle. Int. J. Biol. Macromol. 2018, 107, 1348-1363. [CrossRef] 
105. Serafín, V.; Valverde, A.; Martínez-García, G.; Martínez-Perinán, E.; Comba, F.; Garranzo-Asensio, M.; Barderas, R.; Yáñez-Sedeño, P.; Campuzano, S.; Pingarrón, J.M. Graphene quantum dots-functionalized multi-walled carbon nanotubes as nanocarriers in electrochemical immunosensing. Determination of IL-13 receptor A2 in colorectal cells and tumor tissues with different metastatic potential. Sens. Actuators B Chem. 2019, 284, 711-722. [CrossRef]

106. Serafín, V.; Valverde, A.; Garranzo-Asensio, M.; Barderas, R.; Campuzano, S.; Yáñez-Sedeño, P.; Pingarrón, J.M. Simultaneous amperometric immunosensing of the metastasis-related biomarkers IL-13R $\alpha 2$ and CDH-17 by using grafted screen-printed electrodes and a composite prepared from quantum dots and carbon nanotubes for signal amplification. Microchim. Acta 2019, 186, 411. [CrossRef]

107. Roushani, M.; Valipour, A. The potentiality of graphene quantum dots functionalized by nitrogen and thiol-doped (GQDs-N-S) to stabilize the antibodies in designing of human chorionic gonadotropin immunosensor. Nanochem. Res. 2019, 4, 20-26. [CrossRef]

108. Huang, J.Y.; Zhao, L.; Lei, W.; Wen, W.; Wang, Y.J.; Bao, T.; Xiong, H.Y.; Zhang, X.H.; Wang, S.F. A high-sensitivity electrochemical aptasensor of carcinoembryonic antigen based on graphene quantum dots-ionic liquid-nafion nanomatrix and DNAzyme-assisted signal amplification strategy. Biosens. Bioelectron. 2018, 99, 28-33. [CrossRef]

109. Shekari, Z.; Zare, H.R.; Falahati, A. Electrochemical sandwich aptasensor for the carcinoembryonic antigen using graphene quantum dots, gold nanoparticles and nitrogen doped graphene modified electrode and exploiting the peroxidase-mimicking activity of a G-quadruplex DNAzyme. Microchim. Acta 2019, 186, 530. [CrossRef]

110. Barati, F.; Arpanaei, A.; Mahmoudifard, M. Highly efficient detection of cancer-derived exosomes using modified core-shell electrospun nanofibers as a capture substrate and antibody immobilized-graphene quantum dots as a signaling agent. Anal. Methods 2020, 12, 3670-3681. [CrossRef] [PubMed]

111. Qian, Z.S.; Shan, X.Y.; Chai, L.J.; Ma, J.J.; Chen, J.R.; Feng, H. A universal fluorescence sensing strategy based on biocompatible graphene quantum dots and graphene oxide for the detection of DNA. Nanoscale 2014, 6, 5671-5674. [CrossRef]

112. Joshi, P.; Waghmode, S. Graphene quantum dot-based on-chip electrochemical DNA hybridization sensor for pancreatic cancer. Rep. Electrochem. 2016, 6, 31-40. [CrossRef]

113. Meng, L.; Xiao, K.; Zhang, X.; Du, C.; Chen, J. A novel signal-off photoelectrochemical biosensor for M.SssI MTase activity assay based on GQDs@ZIF-8 polyhedra as signal quencher. Biosens. Bioelectron. 2020, 150, 111861. [CrossRef] [PubMed]

114. Pothipor, C.; Jakmunee, J.; Bamrungsap, S.; Ounnunkad, K. An electrochemical biosensor for simultaneous detection of breast cancer clinically related microRNAs based on a gold nanoparticles/graphene quantum dots/graphene oxide film. Analyst 2021, 146, 4000-4009. [CrossRef] [PubMed]

115. Xi, J.; Xie, C.; Zhang, Y.; Wang, L.; Xiao, J.; Duan, X.; Ren, J.; Xiao, F.; Wang, S. Pd Nanoparticles Decorated N-Doped Graphene Quantum Dots@N-Doped Carbon Hollow Nanospheres with High Electrochemical Sensing Performance in Cancer Detection. ACS Appl. Mater. Interfaces 2016, 8, 22563-22573. [CrossRef] [PubMed]

116. Ge, S.; Lan, F.; Liang, L.; Ren, N.; Li, L.; Liu, H.; Yan, M.; Yu, J. Ultrasensitive Photoelectrochemical Biosensing of Cell Surface N-Glycan Expression Based on the Enhancement of Nanogold-Assembled Mesoporous Silica Amplified by Graphene Quantum Dots and Hybridization Chain Reaction. ACS Appl. Mater. Interfaces 2017, 9, 6670-6678. [CrossRef] [PubMed]

117. Cui, F.; Ji, J.; Sun, J.; Wang, J.; Wang, H.; Zhang, Y.; Ding, H.; Lu, Y.; Xu, D.; Sun, X. A novel magnetic fluorescent biosensor based on graphene quantum dots for rapid, efficient, and sensitive separation and detection of circulating tumor cells. Anal. Bioanal. Chem. 2019, 411, 985-995. [CrossRef]

118. Kim, J.W.; Dang, C.V. Cancer's molecular sweet tooth and the warburg effect. Cancer Res. 2006, 66, 8927-8930. [CrossRef]

119. Tabassum, R.; Jeong, N.Y.; Jung, J. Therapeutic importance of hydrogen sulfide in age-associated neurodegenerative diseases. Neural Regen. Res. 2020, 15, 653-662. [CrossRef]

120. Kashfi, K. The dichotomous role of H2S in cancer cell biology? Déjà vu all over again. Biochem. Pharmacol. 2018, 149, 205-223. [CrossRef]

121. Narayanaswamy, N.; Govindaraju, T. Aldazine-based colorimetric sensors for $\mathrm{Cu}^{2+}$ and $\mathrm{Fe}^{3+}$. Sens. Actuators B Chem. 2012, 161, 304-310. [CrossRef]

122. Cristea, C.; Florea, A.; Tertiș, M.; Săndulescu, R. Immunosensors. In Biosensors-Micro and Nanoscale Biosensors Applications; IntechOpen: London, UK, 2015.

123. Thomas, P.; Gangopadhyay, A.; Steele, G.; Andrews, C.; Nakazato, H.; Oikawa, S.; Jessup, J.M. The effect of transfection of the CEA gene on the metastatic behavior of the human colorectal cancer cell line MIP-101. Cancer Lett. 1995, 92, 59-66. [CrossRef]

124. Stovold, R.; Blackhall, F.; Meredith, S.; Hou, J.M.; Dive, C.; White, A. Biomarkers for small cell lung cancer: Neuroendocrine, epithelial and circulating tumour cells. Lung Cancer 2012, 76, 263-268. [CrossRef]

125. Hasanzadeh, M.; Shadjou, N.; de la Guardia, M. Aptamer-based assay of biomolecules: Recent advances in electro-analytical approach. TrAC Trends Anal. Chem. 2017, 89, 119-132. [CrossRef]

126. Ventura, A.; Kirsch, D.G.; McLaughlin, M.E.; Tuveson, D.A.; Grimm, J.; Lintault, L.; Newman, J.; Reczek, E.E.; Weissleder, R.; Jacks, T. Restoration of p53 function leads to tumour regression in vivo. Nature 2007, 445, 661-665. [CrossRef] [PubMed]

127. Iijima, S. Helical microtubules of graphitic carbon. Nature 1991, 354, 56-58. [CrossRef]

128. Okamoto, H.; Yoshimatsu, Y.; Tomizawa, T.; Kunita, A.; Takayama, R.; Morikawa, T.; Komura, D.; Takahashi, K.; Oshima, T.; Sato, M.; et al. Interleukin-13 receptor $\alpha 2$ is a novel marker and potential therapeutic target for human melanoma. Sci. Rep. 2019, 9, 1281. [CrossRef] [PubMed] 
129. Altree-Tacha, D.; Tyrrell, J.; Haas, T. CDH17 is a more sensitive marker for gastric adenocarcinoma than CK20 and CDX2. Arch. Pathol. Lab. Med. 2017, 141, 144-150. [CrossRef]

130. Stenman, U.H.; Alfthan, H.; Hotakainen, K. Human chorionic gonadotropin in cancer. Clin. Biochem. 2004, 37, 549-561. [CrossRef] [PubMed]

131. Kang, J.; Kim, M.G. Advancements in DNA-assisted Immunosensors. Biochip. J. 2020, 14, 18-31. [CrossRef]

132. Nezlin, R. Use of aptamers in immunoassays. Mol. Immunol. 2016, 70, 149-154. [CrossRef]

133. Iliuk, A.B.; Hu, L.; Tao, W.A. Aptamer in bioanalytical applications. Anal. Chem. 2011, 83, 4440-4452. [CrossRef]

134. Tabar, G.R.H.; Smith, C. DNA aptamers selected as molecular probes for diagnosis of cancerous cells. World Appl. Sci. J. 2010, 8, $16-21$.

135. Zhou, Z.M.; Zhou, J.; Chen, J.; Yu, R.N.; Zhang, M.Z.; Song, J.T.; Zhao, Y. Di Carcino-embryonic antigen detection based on fluorescence resonance energy transfer between quantum dots and graphene oxide. Biosens. Bioelectron. 2014, 59, 397-403. [CrossRef]

136. Dai, J.; Su, Y.; Zhong, S.; Cong, L.; Liu, B.; Yang, J.; Tao, Y.; He, Z.; Chen, C.; Jiang, Y. Exosomes: Key players in cancer and potential therapeutic strategy. Signal Transduct. Target. Ther. 2020, 5, 145. [CrossRef]

137. Wu, Y.; Zeng, H.; Yu, Q.; Huang, H.; Fervers, B.; Chen, Z.; Lu, L. A Circulating Exosome RNA Signature Is a Potential Diagnostic Marker for Pancreatic Cancer, a Systematic Study. Cancers 2021, 13, 2565. [CrossRef] [PubMed]

138. Dobhal, G.; Ayupova, D.; Laufersky, G.; Ayed, Z.; Nann, T.; Goreham, R.V. Cadmium-free quantum dots as fluorescent labels for exosomes. Sensors 2018, 18, 3308. [CrossRef] [PubMed]

139. Zhang, N. Gold-carbon dots for the intracellular imaging of cancer-derived exosomes. 2D Mater. 2020, 13, 7854-7864.

140. Rashid, J.I.A.; Yusof, N.A. The strategies of DNA immobilization and hybridization detection mechanism in the construction of electrochemical DNA sensor: A review. Sens. Bio-Sens. Res. 2017, 16, 19-31. [CrossRef]

141. Dong, D.; Zhang, J.; Zhang, R.; Li, F.; Li, Y.; Jia, Y. Multiprobe Assay for Clinical SEPT9 Methylation Based on the Carbon Dot-Modified Liquid-Exfoliated Graphene Field Effect Transistor with a Potential to Present a Methylation Panorama. ACS Omega 2020, 5, 16228-16237. [CrossRef]

142. Condrat, C.E.; Thompson, D.C.; Barbu, M.G.; Bugnar, O.L.; Boboc, A.; Cretoiu, D.; Suciu, N.; Cretoiu, S.M.; Voinea, S.C. miRNAs as Biomarkers in Disease: Latest Findings Regarding Their Role in Diagnosis and Prognosis. Cells 2020, 9, 276. [CrossRef] [PubMed]

143. Costa, C.; Abal, M.; López-López, R.; Muinelo-Romay, L. Biosensors for the detection of circulating tumour cells. Sensors 2014, 14, 4856-4875. [CrossRef]

144. Lisanti, M.P.; Martinez-Outschoorn, U.E.; Lin, Z.; Pavlides, S.; Whitaker-Menezes, D.; Pestell, R.G.; Howell, A.; Sotgia, F. Hydrogen peroxide fuels aging, inflammation, cancer metabolism and metastasis: The seed and soil also needs "fertilizer". Cell Cycle 2011, 10, 2440-2449. [CrossRef]

145. Yang, C.; Hu, L.W.; Zhu, H.Y.; Ling, Y.; Tao, J.H.; Xu, C.X. RGO quantum dots/ZnO hybrid nanofibers fabricated using electrospun polymer templates and applications in drug screening involving an intracellular $\mathrm{H}_{2} \mathrm{O}_{2}$ sensor. J. Mater. Chem. B 2015, 3, 2651-2659. [CrossRef] [PubMed]

146. Wang, J.; Wang, X.; Tang, H.; Gao, Z.; He, S.; Li, J.; Han, S. Ultrasensitive electrochemical detection of tumor cells based on multiple layer CdS quantum dots-functionalized polystyrene microspheres and graphene oxide-Polyaniline composite. Biosens. Bioelectron. 2018, 100, 1-7. [CrossRef] [PubMed]

147. Pearce, O.M.T. Cancer glycan epitopes: Biosynthesis, structure and function. Glycobiology 2018, 28, 670-696. [CrossRef] [PubMed] 